Article

\title{
Application of IDeS (Industrial Design Structure) to Sustainable Mobility: Case Study of an Innovative Bicycle
}

\author{
Leonardo Frizziero ${ }^{1, *(0)}$, Alfredo Liverani ${ }^{1}\left(\mathbb{D}\right.$, Giampiero Donnici $\left.{ }^{1} * \mathbb{(}\right)$, Ilaria Giuliano ${ }^{1}$, \\ Maria Grazia Picciariello ${ }^{1}$, Maria Luigia Tucci ${ }^{1}$, Donald Reimer ${ }^{2}$ and Ahad Ali ${ }^{2}$ \\ 1 Department of Industrial Engineering, Alma Mater Studiorum University of Bologna, Viale Risorgimento, \\ 2-I-40136, 40136 Bologna, Italy; alfredo.liverani@unibo.it (A.L.); ilaria.giuliano@studio.unibo.it (I.G.); \\ maria.picciariello@studio.unibo.it (M.G.P.); marialuigia.tucci@studio.unibo.it (M.L.T.) \\ 2 A. Leon Linton Department of Mechanical, Robotics and Industrial Engineering, Lawrence Technological \\ University, 21000 West Ten Mile Road, Southfield, MI 48075-1058, USA; dreimer@ltu.edu (D.R.); \\ sali@ltu.edu (A.A.) \\ * Correspondence: leonardo.frizziero@unibo.it (L.F.); giampiero.donnici@unibo.it (G.D.)
}

check for updates

Citation: Frizziero, L.; Liverani, A.; Donnici, G.; Giuliano, I.; Picciariello, M.G.; Tucci, M.L.; Reimer, D.; Ali, A. Application of IDeS (Industrial Design Structure) to Sustainable Mobility: Case Study of an Innovative Bicycle. Inventions 2021, 6, 22. https://doi.org/10.3390/

inventions6020022

Academic Editor: Biswajit Sarkar

Received: 9 February 2021

Accepted: 24 March 2021

Published: 26 March 2021

Publisher's Note: MDPI stays neutra with regard to jurisdictional claims in published maps and institutional affiliations.

Copyright: (c) 2021 by the authors. Licensee MDPI, Basel, Switzerland. This article is an open access article distributed under the terms and conditions of the Creative Commons Attribution (CC BY) license (https:// creativecommons.org/licenses/by/ $4.0 /)$

\begin{abstract}
The present study aims to validate a new research method called IDeS (industrial design structure) through the design of an electric bicycle for everyday city life. IDeS is the latest evolution of a combination of innovative and advanced systematic approaches that are used to set a new industrial project. The IDeS methodology is sequentially composed of quality function deployment (QFD), benchmarking (BM), top-flop analysis (TFA), stylistic design engineering (SDE), design for $\mathrm{X}$, prototyping and testing, budgeting, and planning. The present work illustrates how to integrate the abovementioned design methods and achieve a convincing result. In going through the IDeS method step by step, we compare the different solutions on the market in order to understand which are the best performing products and to understand what is missing on the market. This method allowed us to design a bicycle that is as close as possible to the "ideal bike", obtained with the top/flop analysis.
\end{abstract}

Keywords: industrial design structure (IDeS); quality function deployment (QFD); benchmarking (BM); top-flop analysis (TFA); stylistic design engineering (SDE); sustainable mobility; sustainable design

\section{Introduction}

We present a case study based on the integration and the evolution of relevant systematic design methods in literature (Caligiana et al., 2017, Frizziero et al. 2019, Donnici et al. 2019), where quality function deployment (QFD) is added to TRIZ, benchmarking, top-flop analysis, and stylistic design engineering. Here, the famous DFSS (design for six sigma) approach evolves into an approach we refer to as industrial design structure (IDeS). The abovementioned works demonstrate how it is possible to have a more integrated and complete method for developing new industrial projects using IDeS, which covers all the industrial phases, starting from the project setup, to the product development stage, finally ending with the production startup. The present paper illustrates the application of the first two main phases; the final production startup will not be covered here.

In order to formalize the method used, we chose as a case study the design of an electric bike. The IDeS method follows a well-defined analytical ladder and is useful for designing a valid product on the market. The choice fell precisely on an electric bike (e-bike) because e-bikes have now become a widespread means of transportation, especially in the urban environment. Very often, these means of transportation are associated with the idea of scooters with pedals, where the user simply presses a button to start the engine. However, this is not the concept employed for an electric bike, which works in a completely different way from such a model. The e-bike that is introduced here attempts to reshape the habits of city inhabitants, who as a result of this innovative project can opt for a 
sustainable and also practical alternative simultaneously, without having to give up their daily activities.

The paper is divided into sections that follow the structure of the IDeS method. Our design setting starts from the environmental analysis, which is useful to define the reference area in which we operate, followed by the whole analytical part of the method. This step helps us to compare the existing engineering solutions in terms of engine position and battery; from this, we define the style based on the study of the classic lines of design. Once we defined the design, we realize it through rapid prototyping while reflecting on future developments. In terms of design, this bicycle represents the synthesis of three models, i.e., city, folding, and cargo, and accordingly the article concludes with a reflection on the constant improvement of the three models.

\section{Materials and Methods of Industrial Design Structure (IDeS)}

\subsection{Design Setup}

The structure of the present work is based on IDeS, i.e., industrial design structure, which is the latest evolution of combining innovative and systematic design methodologies such as quality function deployment (QFD) [1], benchmarking, top-flop analysis, stylistic design engineering (SDE), etc.

The application of IDeS towards the present work can be structured in the following road map, which summarizes the process involved (see Figure 1).

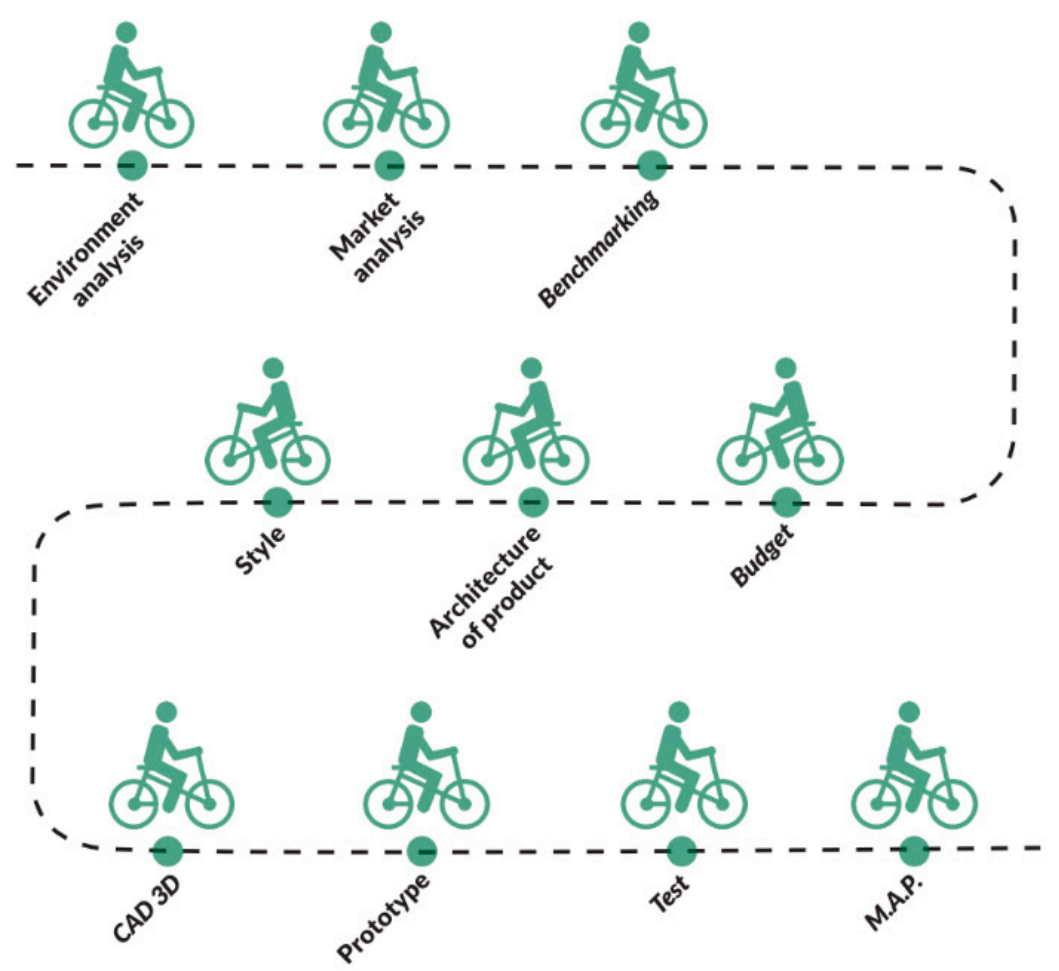

Figure 1. The road map of the industrial design structure (IDeS) project.

IDeS is generally structured into three main steps, i.e., project setup, product development, and production startup. Designers are usually involved mostly in the first two steps, during which the new product is born and takes its shape throughout the project.

The project setup stage is composed of many phases:

(a) Environment analysis

(b) Market analysis

(c) Benchmarking

(d) Styling

(e) Architecture of the product 
(f) Budgeting and planning

Product development is composed of the following phases:

(a) 3D modelling (CAD)

(b) Prototyping

(c) Testing

(d) Optimization (i.e., MAP, which stands for "messa a punto" in Italian)

The present work is structured according to all the phases of the project setup and product development stages by showing the application to the case study using the methodology presented and then offering an innovative solution to the issue of sustainable mobility.

\subsubsection{Environment Analysis}

The environment analysis is useful for knowing how the reference product is situated. We need to have a complete picture of the environment in which we are going to design so as to develop a product that is appropriate to the reference market.

\subsubsection{Quality Function Deployment Methodology (QFD)}

QFD, which stands for quality function deployment, is a market analysis methodology that aims to design and optimize the process of developing new products based on customer needs. It involves two components, namely six wh-questions (i.e., who, what, how, when, where, why) and interrelation matrices (i.e., the matrix of relative importance and the dependence-independence matrix)

First, the 6 wh-questions are asked to better define the reference context and thus identify a list of qualitative requirements that the product should have. Subsequently, the requirements are interpolated into a matrix, the matrix of relative importance, in which a number from 0 to 2 is assigned to each box of the matrix based on the importance that is recognized at each interpolation of requirements: 0 is assigned if the row requirement is more important than the column requirement; 2 is assigned if the column requirement is deemed to be more important; and 1 is assigned if they are both considered important. By adding up the values of each column, a ranking of the requirements is obtained, from the most important, with the greatest numerical value, to the least important.

As regards the independence matrix, the interpolated requirements are assigned values $(0,1,3,9)$ based on how much the row requirement is dependent on or independent of the column requirement: 0 is assigned if the row requirement is completely independent from the column requirement is assigned the number 0; 1 is assigned if it is not very dependent; 3 is assigned if it is very dependent, and 9 is assigned if it is completely dependent on the column requirement. In this case, adding the values of each column gives us a classification of the requirements, from the most independent, with the largest numerical value, to the most dependent.

Finally, the four requirements with the highest values of each matrix are taken into account in order to create a new skimmed list of the most relevant qualitative requirements.

\subsubsection{Benchmarking}

Benchmarking is the methodology used to analyze the products of competition on the market. With this method, the technical and qualitative characteristics considered most relevant for each product are analyzed and compared. Consequently, the top-flop analysis is carried out by comparing quantitatively the best and worst characteristics summarized by benchmarking. From the difference between top and flop, the result with the highest numerical value describes the minimum number of innovative features that the new product must have.

To improve as many parameters as possible and have a higher degree of innovation, the features used in benchmarking are interpolated with the requirements extrapolated from the first two matrices into a new matrix, i.e., the what-how matrix. Each cell is assigned a number from 0 to $10(0,2,4,6,8,10)$ based on how each feature influences the 
individual requirements. By adding the values of each column, the design drivers that need to be considered in order to improve innovation are highlighted.

\subsubsection{Planning}

In order to organize and plan work activities, a Gantt plan was used, which is a visual scheme that allows users to have a complete overview on the structure of the project and its timing. The list of activities is placed on the vertical axis, while the timing of development is placed on the horizontal axis; this timing can be days, weeks, or months, depending on the project timeline. Each task is displayed with a colored bar that indicates the task managers, and it extends from the start date to the end of the task. With this organization, we are allowed to visualize the workflow and the potential technical criticalities, and we are also able to understand whether the workflow is in line with the deadline.

\subsubsection{Budget}

Through budget planning, it was possible for us to get a forecast of the costs related to the design activities. The costs of research and development include the materials to build the product, the cost of human resources based on the hours of work and the tasks needed to be performed, the cost of machinery and manufacturing processes, and the costs of prototyping and its equipment.

\subsubsection{Product Architecture}

This part allows the designer to look at the functional part and at the aesthetics of the project at the same time but not in a specific way. This is useful to creating a solid base for a good project, which can then be used to create the entire system with all the details.

\subsubsection{Stylistic Design Engineering (SDE)}

The SDE process concludes the project setting phase, and it can be analyzed in different steps. The first step looks at various design style references in order to understand which characteristics (such as colors, shapes, etc.) can be used to create an innovative product. The second step consists of making sketches of the ideal product. Then, the third step defines the dimensions of the product using 2D and 3D modelling software. The fourth step focuses only on the 3D models, and the fifth and final step creates renders using suitable software.

\subsection{Product Development}

The first part of this phase consists of determining the technologies, materials, and dimensions to be used by making a digital model of the project. Following this, the second part of this phase covers the testing and the prototyping sections.

\subsubsection{Design Engineering}

This step comprises different parts, namely choosing the shape, dimensions, and materials of the product; these parts can be done using 2D and 3D modelling software. After this first part, the project can continue with defining other details, such as the items and the usability.

\subsubsection{Prototyping}

This prototyping phase is one of the most crucial parts of the IDeS method, as it is used for visualizing the project from a different point of view, and different prototypes are used here. The first one is a digital one made with CAD (COMPUTER AIDED DESIGN) software, meaning that every modification can be made easily by changing the parameters. The second one is an aesthetic prototype made with rendering software or other types of technologies such as 3D printing. The third one is a functional prototype that helps with understanding whether the dimensions of the projects are accurate using a 1:1 scale model. The fourth and final one is a virtual prototype, but it is not always used; in fact, 
augmented reality can be used to test different models at one time. If the project is a service, the development needs a prototype made with a different kind of software than the vector graphic ones.

\subsubsection{Testing}

The testing step shows the standard of innovation. To understand it, the top-flop analysis should be recalculated at this stage. After that, the old highest value of $\Delta$ must be compared to the new one. In short, this part consists of looking at the prototypes to assess all of their characteristics.

\subsubsection{Setup}

This phase consists of collecting data to modify the project and improve it. It could be done by reviewing its features. This part, as well as the next one, can be repeated even if the product is already produced.

\subsubsection{Redesign}

At the end of all the previous stages, the IDeS method can be concluded with the redesign step, which means reviewing the last two parts of the method to improve the project.

\section{Case Study}

In the following section of the article, we present some considerations on the application of the IDeS method. We applied it point by point and collected the data necessary for the development of a new product.

\subsection{Design Setup}

At the beginning of the definition of the project, we did research on the field of sustainable mobility and e-bikes in particular. We studied how much their usage have spread compared to cars; this step was performed using the QFD method and the what-how matrix, both of which helped us to start the design.

\subsubsection{Environment Analysis}

With our analysis of the environment, we examined sustainable mobility and specifically studied the innovative means of transport that meet the new needs of those who travel or commute around in the city. First of all, it is useful to analyze the differences between electric and assisted bikes, given that the two are often mixed up. In actuality, these two represent two different means of transportation.

Pedal-assisted bicycles (often abbreviated as e-bikes) are exempt from insurance costs and, above all, from continuous increases in fuel costs; they do not pollute, have no parking problems, and allow users to make less effort than traditional bicycles.

Figure 2 presents information on the cycling market in Italy, given by Legambiente in the second A Bi Ci report, which stated the amount of money produced by sustainable mobility and a growth perspective if public actors invest seriously in alternative means of transportation. The internal product bike (IPB), which is the turnover generated by "combined pedal movements", is over 6.2 billion euros a year, but the actual number could be over 22 billion. Bike-friendly cities are growing, and there is increasing attention given to cycling, which stands in contrast to the widespread thought that Italy is falling behind the group of countries with the most cycling performed [2].

Cycling tourism is a form of cycling, with variants such as taking the train with a bicycle or with tours organized by agencies that provide logistical support and luggage transport. It is a particularly inexpensive way of travelling, which goes beyond the usual standards and routes of mass tourism. The practitioners, called cyclists, are almost always united by a strong environmental sensitivity, a great passion for cycling as a mean of transportation and as a way of life, a lively curiosity for unknown places, and a great adaptability to unexpected situations. 


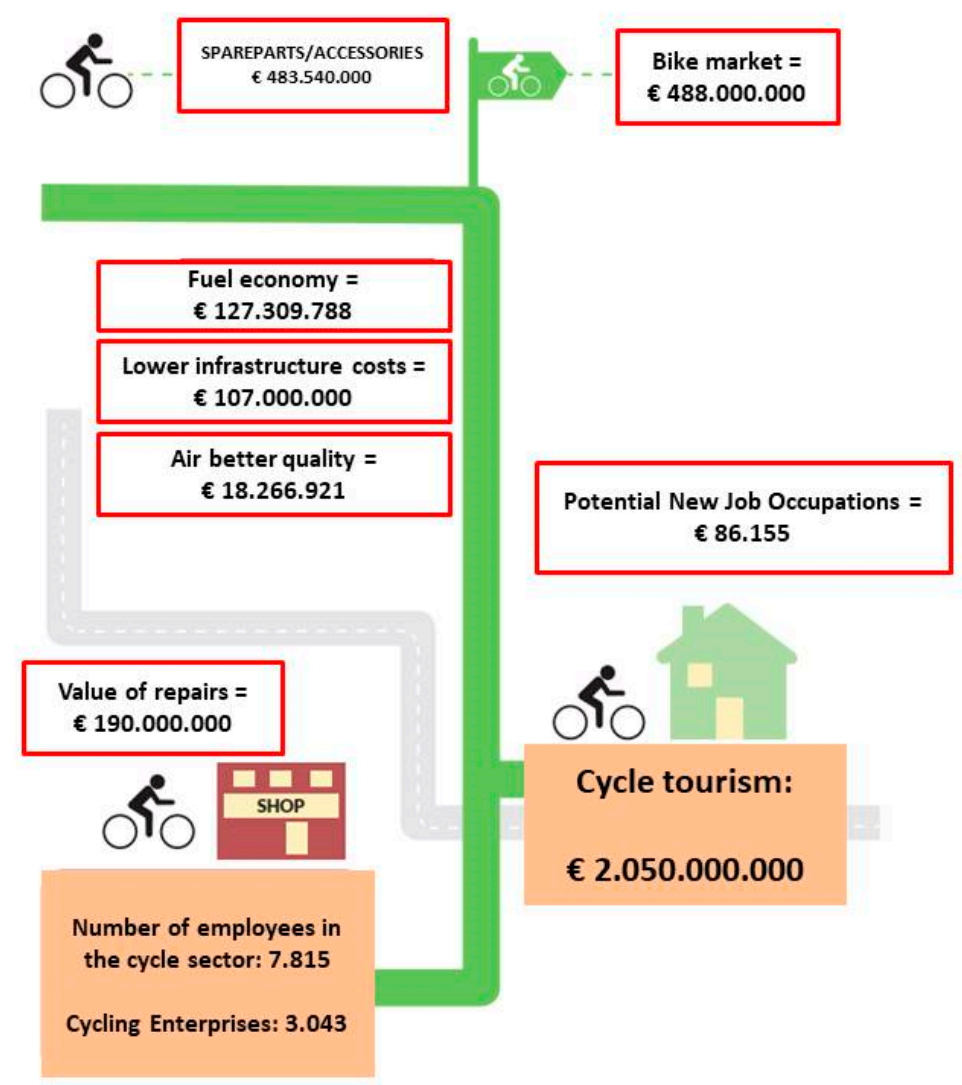

Figure 2. IPB (Internal Product Bike) structure.

\subsubsection{Quality Function Deployment Methodology (QFD)}

We first used six wh-questions of the QFD methodology to determine a list of characteristics that delineate a bicycle.

1. Who will use the product?

- Adults aged between 18 and 70, mostly with financial opportunities

- Adults who commute around the city and prefer not to use the car

2. When will the product be used?

- Central hours of the day to avoid car traffic

- Working days of the week

- Daily, as a mean of transportation to go to work or to use in leisure time

3. Why will the product be used?

- To reduce fuel consumption

- To reduce time spent in traffic

- For medium-length travel, to avoid traffic and reduce stress without missing out on the experience of owning a mean of transportation

4. What is the product for?

- To move around town quickly

- To reduce the energy footprint in the environment

- To be used by tourists

5. How do users use the product?

- Like a normal bike, but with an electric motor

- Combined with other modes of transportation, as the bike can be easily transported

6. Where do users use the product?

- In very busy cities 
- From suburban areas to reach the city center

To sum up, the list of features is made up of the following traits: (1) equipped, (2) fast, (3) economical, (4) compact, (5) hybrid, (6) light, (7) safe, (8) autonomous, (9) versatile, (10) transportable, (11) stable, and (12) ecological. Due to the characteristics that we found, we were able to fill the relationship matrix, which gives us indications on what the most important features of the product are. The relative importance relationship matrix (Table 1) is filled in as follows: 0 when the row is most important than column; 1 when both row and column are equally important; and 2 when the row is less important than column. After adding up the values on the column, we obtained a chart of the most important requirements that we believe customers desire (see Table 1).

Table 1. Relative importance relationship matrix.

\begin{tabular}{|c|c|c|c|c|c|c|c|c|c|c|c|c|}
\hline & 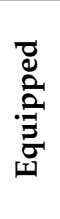 & $\begin{array}{l}\overrightarrow{5} \\
\text { 童 }\end{array}$ & 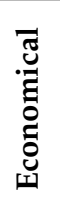 & 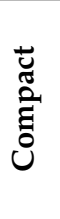 & 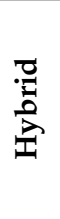 & 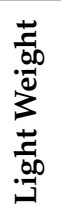 & 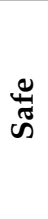 & 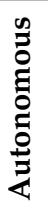 & $\begin{array}{l}\frac{0}{0} \\
\frac{\pi}{0} \\
\frac{\pi}{2} \\
\frac{\pi}{2}\end{array}$ & 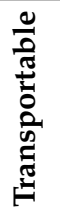 & $\frac{\frac{0}{0}}{\frac{\pi}{\pi}}$ & 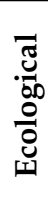 \\
\hline Equipped & 1 & 0 & 0 & 2 & 0 & 2 & 0 & 0 & 2 & 2 & 0 & 1 \\
\hline Fast & 2 & 1 & 2 & 2 & 0 & 2 & 2 & 1 & 2 & 2 & 1 & 2 \\
\hline Economical & 2 & 0 & 1 & 2 & 0 & 2 & 0 & 0 & 2 & 2 & 1 & 1 \\
\hline Compact & 0 & 0 & 0 & 1 & 0 & 1 & 0 & 0 & 2 & 1 & 0 & 1 \\
\hline Hybrid & 2 & 2 & 2 & 2 & 1 & 2 & 2 & 1 & 2 & 2 & 2 & 1 \\
\hline Lightweight & 0 & 0 & 0 & 1 & 0 & 1 & 0 & 0 & 1 & 1 & 0 & 0 \\
\hline Safe & 2 & 0 & 2 & 2 & 0 & 2 & 1 & 0 & 2 & 2 & 1 & 2 \\
\hline Autonomous & 2 & 1 & 2 & 2 & 1 & 2 & 2 & 1 & 2 & 2 & 2 & 1 \\
\hline Adaptable & 0 & 0 & 0 & 0 & 0 & 1 & 0 & 0 & 1 & 1 & 0 & 0 \\
\hline Transportable & 0 & 0 & 0 & 1 & 0 & 1 & 0 & 0 & 1 & 1 & 0 & 0 \\
\hline Stable & 2 & 1 & 1 & 2 & 0 & 2 & 1 & 0 & 2 & 2 & 1 & 2 \\
\hline Ecological & 1 & 0 & 1 & 1 & 1 & 2 & 0 & 1 & 2 & 2 & 0 & 1 \\
\hline Total & 14 & 5 & 11 & 18 & 3 & 20 & 8 & 4 & 21 & 20 & 8 & 12 \\
\hline
\end{tabular}

Below is a short explanation of how the numerical values were assigned: 0 is assigned if the prerequisite of the row is more crucial than the one of the column; 1 is assigned if the prerequisite of the row and the one of the column are both significant; and 2 is assigned if the requirement of the row is less important than the one of the column.

After the compilation of the table, all the numerical values of the columns were added, and the highest sums were highlighted. In our case, the characteristics that have the greatest value are compactness, lightness, versatility, and transportability. The requirements highlighted here are those that will have a greater importance in defining the design of the product.

In the same way, in the relationship matrix of dependence/independence (Table 1), every unit has to be filled with a numerical value from 0 to 9 that define how much the characteristics of the rows are more or less dependent on the ones in the columns. We assign 0 if the prerequisite of the row is completely independent from the one of the column; 1 if the prerequisite of the row is not so dependent on the one of the column; 3 if the prerequisite of the row is very dependent on the one of the column; and 9 if the prerequisite of the row is completely dependent on the one of the column.

At the end of this analysis, we calculated the sum of the numeric values in each column of the table. In this way, we obtained a list of the most independent requirements of our project, i.e., equipped, economical, light, and stable (see Table 2). 
Table 2. Matrix of independence/dependence.

\begin{tabular}{|c|c|c|c|c|c|c|c|c|c|c|c|c|c|}
\hline & 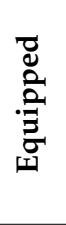 & 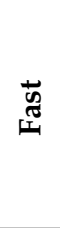 & 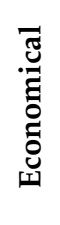 & $\begin{array}{l}\stackrel{\ddot{t}}{\sigma} \\
\stackrel{0}{\Xi} \\
\tilde{0}\end{array}$ & $\begin{array}{l}\frac{\pi}{2} \\
\frac{0}{2}\end{array}$ & 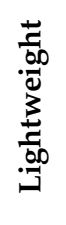 & 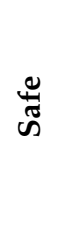 & 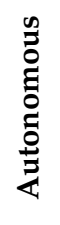 & $\frac{\frac{0}{0}}{\frac{\pi}{0}}$ & 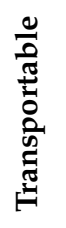 & $\frac{\frac{0}{0}}{\tilde{\pi}}$ & 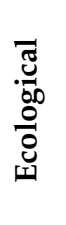 & స్తే \\
\hline Equipped & 9 & 0 & 9 & 3 & 0 & 3 & 0 & 0 & 3 & 3 & 1 & 0 & 31 \\
\hline Fast & 3 & 9 & 1 & 3 & 3 & 9 & 0 & 0 & 1 & 1 & 9 & 0 & 39 \\
\hline Economical & 9 & 1 & 9 & 0 & 1 & 9 & 9 & 9 & 3 & 3 & 3 & 9 & 65 \\
\hline Compact & 3 & 0 & 1 & 9 & 0 & 1 & 0 & 0 & 3 & 9 & 9 & 0 & 35 \\
\hline Hibrid & 0 & 0 & 3 & 0 & 9 & 0 & 0 & 3 & 0 & 0 & 0 & 3 & 18 \\
\hline Lightweight & 9 & 0 & 9 & 3 & 0 & 9 & 1 & 0 & 1 & 9 & 3 & 0 & 44 \\
\hline Safe & 3 & 9 & 3 & 0 & 0 & 0 & 9 & 1 & 0 & 0 & 9 & 0 & 34 \\
\hline Autonomous & 0 & 3 & 9 & 0 & 3 & 0 & 0 & 9 & 1 & 0 & 0 & 9 & 34 \\
\hline Adaptable & 9 & 0 & 9 & 3 & 0 & 3 & 0 & 1 & 9 & 3 & 0 & 0 & 37 \\
\hline Transportable & 9 & 0 & 3 & 9 & 0 & 9 & 0 & 0 & 0 & 9 & 0 & 0 & 39 \\
\hline Stable & 3 & 9 & 3 & 3 & 0 & 3 & 3 & 0 & 0 & 0 & 9 & 0 & 33 \\
\hline Ecological & 0 & 0 & 3 & 0 & 3 & 0 & 0 & 3 & 1 & 1 & 0 & 9 & 20 \\
\hline Total & 57 & 31 & 62 & 33 & 19 & 46 & 22 & 26 & 22 & 38 & 43 & 30 & \\
\hline
\end{tabular}

Considering the first four requirements of the matrix of relative importance and the first four of the second one, we determined a list of project characteristics. It was decided that the bike is to be a product rich in accessories and customization elements that do not affect the price, and the stability and safety of the bike is also of top concern. We intend for our electric bike to be versatile enough to adapt to medium-long distances without sacrificing compactness and therefore the fluidity of driving/pedaling.

\subsubsection{Benchmarking}

For the analysis of competitors and benchmarking, a distinction was made among the categories in order to be able to choose those most suitable for design. The product categories were divided into the following: mountain e-bikes (e-Mtb), city e-bikes (e-City), trekking e-bikes (e-Trekking), racing e-bikes (e-Strada), folding e-bikes (e-Folding), and cargo e-bikes (e-Cargo). Benchmarking, however, was only carried out on the e-City, e-Folding, and e-Cargo categories as the environmental analysis focuses mainly on urban activities.

E-bikes for the city are the first type of electric bikes that is often considered by consumers, as it is the segment that has had the greatest expansion and diffusion in the world. In Italy, we are witnessing a remarkable development for these bikes, and there are increasingly more users who choose to use city e-bikes to move around the city, go to work, and run errands. While electric folding bikes may not be as popular, they are constantly evolving because an increasingly large market is looking for the compactness and comfort of a bike that can fold but can also provide help with a pedal-assisted mechanism. Folding bikes can be closed and parked in a very small space. The last type we considered is cargo e-bikes. Already widely used in Northern Europe and now in strong expansion also in Italy, cargo e-bikes are designed to be robust, reliable, and above all capacious. Generally, there are two types: those with a front-loading space in front of the handlebars and those with a rear load, with luggage racks and storage compartments of great capacity.

With regard to the choice of the characteristics analyzed in benchmarking, more attention was paid to wheel size, battery life, engine position, battery position, operating voltage, charging time, on-board computer, weight, and price. The position of the engine 
on the anatomy of the bike also determines its characteristics. Currently there are 4 main types: (1) motor in the hub (it is a part of the wheel that allows for rotational movement and therefore the advancement of the bike itself), which consists essentially of two parts of the front or rear wheel; (2) an engine near or in place of the central movement box (called central motor); (3) an invisible motor hidden inside of external components or inside the column (it is the part of the frame that supports the central movement and the seat post); and (4) the engine near the front or rear tire (called clutch motor) [3]. As far as the battery is concerned, the most important parameter for assessing its autonomy is its capacity, which is measured in watt hour (Wh). It indicates how many watts it can deliver in the time interval of one hour. Another important element to consider is the working voltage (measured in volts) of a battery that determines the maximum speed of rotation of the engine. An e-bike can generally run at 24,36 , or $48 \mathrm{~V}$.

The control console of an electric bicycle can be considered as the part with its speaking and hearing functionalities, if we were to use an anatomical metaphor. Technological evolution has differentiated them into three families. The first is the analog console, equipped only with switches to adjust the assistance without providing any information. The second one is the digital console; its buttons and light indicators inform users about the engine status (whether it is running or not), the level of assistance selected, and the residual charge. In the most modern versions, it uses an LCD display and provides computer cycle functionality with GPS and cardio information. The latest family is the Bluetooth digital console; it includes all the advantages of the digital type but can also be connected to smartphones using its potential through dedicated apps.

From the comparison between the best and worst qualities among all those scored in Table 3, we highlighted the so-called "tops" and "flop". Between the number for tops and the number of flops, we calculated the difference and chose the highest score of them all. This score defines the minimum number of characteristics that must be innovated in the product, and in our case the degree of innovation is 6.

In order to reach innovation, we should obtain a product with $\Delta \geq 6$, as determined by the characteristics analyzed in the matrix. We compared the customers' requirements obtained from the relationship matrixes with the innovation characteristics of the product. In particular, the technical innovation characteristics were voted (from 0 to 10) by 100 people chosen among a different population (50\% students; 30\% professionals among $40 \mathrm{~s}$ to $55 \mathrm{~s}$; $20 \%$ old people, mostly retired) a in order to satisfy the customers' requirements; in this way, it was possible to have a list of technical characteristics that become the target for innovation. From the comparison of these requirements, we can elaborate the what/how matrix (Table 4).

This matrix highlights the requirements that must be most innovative among all requirements; these top requirements are wheel dimension, weight, supported loads, and wheel number. Once the benchmarking and different matrices were calculated, we continued with the analysis. From this comparative analysis, we deduced the differential values between the positive and negative characteristics in the column of the various products.

The highest differential value will be the starting point to define the design drivers and the basic requirements of the new innovative electric bicycle. If we read the table of benchmarking on the lines, we could evaluate the characteristics of the ideal bike, which would have all the top values identified in the matrix. In our case, the ideal innovative electric bicycle should have wheels with a large but small diameter, so as to ensure the compactness and versatility of the product. It should have a battery life greater than 500 Wh and the rear engine position at the hub.

In this type of solution, the motor is integrated with the transmission and gives the feeling of a soft and effortless pedaling. The assistance is very high, so the muscle pedaling is minimal compared to the engine thrust: In fact, it is suitable for both urban routes and hiking. The ideal bike (Table 5) should be a link between a lightweight folding and sturdy cargo bike with a load greater than $200 \mathrm{~kg}$ and three large and stable wheels. 
Table 3. Benchmarking table among concurrent products.

\begin{tabular}{|c|c|c|c|c|c|c|c|c|c|c|c|c|}
\hline & 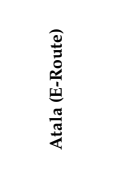 & 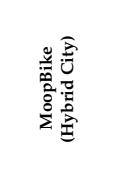 & 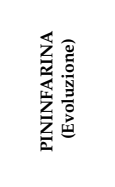 & 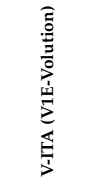 & 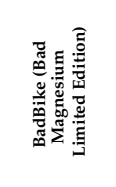 & 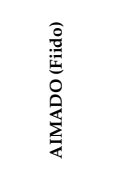 & 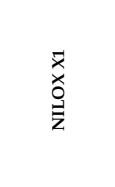 & 感 & 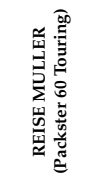 & 象 & 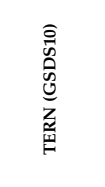 & 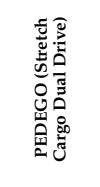 \\
\hline $\begin{array}{c}\text { Wheels } \\
\text { dimension }\end{array}$ & $26^{\prime \prime}$ & $28^{\prime \prime}$ & $28^{\prime \prime}$ & $20^{\prime \prime}$ & $20^{\prime \prime}$ & $14^{\prime \prime}$ & $20^{\prime \prime}$ & $8^{\prime \prime}$ & $20^{\prime \prime}-26^{\prime \prime}$ & $20^{\prime \prime}$ & $20^{\prime \prime}$ & $24^{\prime \prime}$ \\
\hline Battery life & 374 & 160 & 500 & 240 & 468 & 240 & 316 & 138 & 500 & 300 & 500 & 816 \\
\hline $\begin{array}{c}\text { Engine } \\
\text { position }\end{array}$ & Rear hub & Rear hub & Central & Rear hub & Rear hub & Rear hub & Rear hub & Central & Central & Central & Central & Rear hub \\
\hline $\begin{array}{c}\text { Battery } \\
\text { position }\end{array}$ & $\begin{array}{l}\text { Outside the } \\
\text { column }\end{array}$ & Integrated & Integrated & Integrated & $\begin{array}{l}\text { Outside the } \\
\text { column }\end{array}$ & Integrated & Integrated & $\begin{array}{c}\text { Front } \\
\text { outside }\end{array}$ & $\begin{array}{l}\text { Outside in } \\
\text { the triangle }\end{array}$ & $\begin{array}{l}\text { Outside the } \\
\text { column }\end{array}$ & $\begin{array}{c}\text { Semi- } \\
\text { integrated }\end{array}$ & $\begin{array}{l}\text { Outside the } \\
\text { column }\end{array}$ \\
\hline $\begin{array}{l}\text { Operating } \\
\text { voltage } \\
\text { (volt) }\end{array}$ & 36 & 30 & 36 & 36 & 36 & 36 & 36 & 24 & 36 & 48 & 36 & 48 \\
\hline $\begin{array}{l}\text { Charging } \\
\text { time (hours) }\end{array}$ & 5.5 & - & - & $2.5 / 5$ & 5 & 5 & 3 & 2.5 & 4.5 & 3 & - & - \\
\hline $\begin{array}{l}\text { On-board } \\
\text { computer }\end{array}$ & $\begin{array}{l}\text { Analogic } \\
\text { console }\end{array}$ & Bluetooth & Digital & Bluetooth & Digital & Digital & $\begin{array}{l}\text { Analogic } \\
\text { console }\end{array}$ & $\begin{array}{l}\text { Analogic } \\
\text { console }\end{array}$ & Digital & $\begin{array}{l}\text { Analog } \\
\text { console }\end{array}$ & Digital & Bluetooth \\
\hline Weight (kg) & & 11.9 & 17.9 & 16.5 & 25 & 19 & 29 & 12 & 37.1 & 13 & 27 & 40 \\
\hline Price & 919 & 4200 & 6390 & 1400 & 2698 & 668 & 1649 & 360 & 4699 & 3690 & 4200 & 4852 \\
\hline $\begin{array}{l}\text { Supported } \\
\text { loads (kg) }\end{array}$ & $<70$ & & $<95$ & & $<105$ & $<120$ & $<100$ & $<100$ & $<200$ & $<20$ (cargo) & $<200$ & $<181$ \\
\hline $\begin{array}{c}\text { Cargo } \\
\text { position }\end{array}$ & - & - & - & - & - & - & - & - & Front & Front & Back & $\begin{array}{c}\text { Front and } \\
\text { back }\end{array}$ \\
\hline $\begin{array}{c}\text { Wheel } \\
\text { number }\end{array}$ & 2 & 2 & 2 & 2 & 2 & 2 & 2 & 2 & 2 & 3 & 2 & 2 \\
\hline $\begin{array}{c}\text { Number of } \\
\text { seats }\end{array}$ & $1(+1)$ & 1 & 1 & 1 & 2 & 1 & 1 & 1 & 3 & 1 & 3 & 3 \\
\hline $\begin{array}{l}\text { Compact- } \\
\text { ness } \\
\text { (dimen- } \\
\text { sions) }\end{array}$ & & & & & $96 \times 60 \times 70$ & $75 \times 35 \times 65$ & $85 \times 45 \times 70$ & $70 \times 42 \times 21$ & & & & \\
\hline Size & 42 & Custom & 53 & Unique & Unique & Unique & Unique & Unique & Unique & Unique & $\mathrm{S}, \mathrm{M}, \mathrm{L}, \mathrm{XL}$ & 40 \\
\hline $\begin{array}{c}\text { Frame } \\
\text { material }\end{array}$ & Aluminum & $\begin{array}{l}\text { Aluminum } \\
\text { handmade }\end{array}$ & Carbon & $\begin{array}{c}\text { Avionic } \\
\text { aluminum }\end{array}$ & Aluminum & $\begin{array}{l}\text { Aluminum } \\
\text { alloy }\end{array}$ & - & - & Aluminum & Aluminum & Aluminum & Aluminum \\
\hline Brake & V-brake & Rim brake & $\begin{array}{l}\text { Hydraulic } \\
\text { disc brake }\end{array}$ & V-brake & $\begin{array}{l}\text { Hydraulic } \\
\text { disc brake }\end{array}$ & $\begin{array}{l}\text { Mechanical } \\
\text { disc brake }\end{array}$ & V-brake & - & Disc brake & $\begin{array}{l}\text { Hydraulic } \\
\text { disc brake }\end{array}$ & $\begin{array}{l}\text { Hydraulic } \\
\text { disc brake }\end{array}$ & Disc brake \\
\hline Shift & $\begin{array}{c}\text { SH Tourney } \\
1 \times 7\end{array}$ & Single speed & $\begin{array}{c}\text { SH Nexus } \\
\text { (Alfine } 81 \times \\
8 \text { ) }\end{array}$ & 4 speeds & $\begin{array}{l}\text { Shimano } \\
\text { altus } 7 \\
\text { speeds }\end{array}$ & $\begin{array}{l}\text { Shimano } \\
21.3 \times 7\end{array}$ & Single speed & Single speed & $\begin{array}{c}\text { SH Deore } \\
1 \times 10\end{array}$ & & $\begin{array}{l}\text { SH Deore } 1 \\
\times 10\end{array}$ & $\begin{array}{c}\text { SH Acera } \\
\text { tourney } 1 \times \\
7\end{array}$ \\
\hline Top & 2 & 5 & 3 & 4 & 2 & 4 & 2 & 4 & 5 & 3 & 4 & 8 \\
\hline Flop & 3 & 1 & 2 & 2 & 1 & 1 & 4 & 7 & 4 & 4 & 3 & 2 \\
\hline$\Delta$ (Top-Flop) & -1 & 4 & 1 & 2 & 1 & 3 & -2 & -3 & 1 & -1 & -1 & 6 \\
\hline
\end{tabular}

Table 4. What/how matrix.

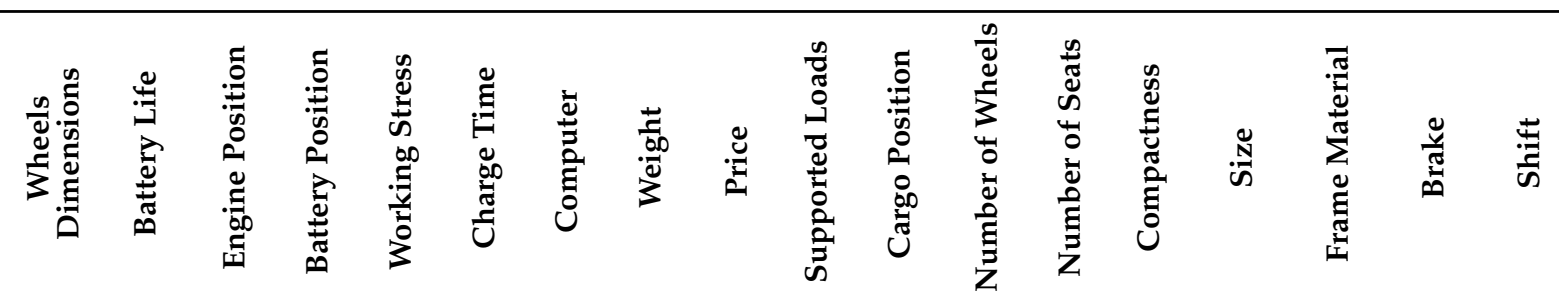

$\begin{array}{lllllllllllllllllll}\text { Compact } & 8 & 0 & 4 & 4 & 0 & 0 & 2 & 2 & 6 & 6 & 8 & 10 & 8 & 10 & 8 & 0 & 0 & 0\end{array}$

$\begin{array}{lllllllllllllllllll}\text { Lightweight } & 8 & 8 & 0 & 0 & 0 & 0 & 2 & 10 & 8 & 8 & 0 & 8 & 2 & 0 & 8 & 10 & 0 & 0\end{array}$

\begin{tabular}{lllllllllllllllllllll} 
Adaptable & 6 & 4 & 2 & 4 & 4 & 6 & 4 & 8 & 8 & 6 & 6 & 4 & 8 & 0 & 0 & 0 & 0 & 6 \\
\hline
\end{tabular}

$\begin{array}{lllllllllllllllllllll}\text { Transportable } & 8 & 0 & 6 & 6 & 0 & 0 & 2 & 8 & 2 & 4 & 6 & 8 & 6 & 10 & 4 & 6 & 0 & 0\end{array}$

\begin{tabular}{cccccccccccccccccccc} 
Equipped & 0 & 0 & 4 & 6 & 0 & 0 & 10 & 0 & 10 & 4 & 2 & 4 & 0 & 0 & 0 & 0 & 0 & 0 \\
\hline Economical & 2 & 8 & 6 & 0 & 0 & 8 & 8 & 6 & 10 & 6 & 0 & 0 & 0 & 0 & 6 & 8 & 6 & 6 \\
\hline Stable & 10 & 0 & 8 & 8 & 0 & 0 & 2 & 6 & 0 & 6 & 8 & 8 & 4 & 4 & 2 & 2 & 8 & 4 \\
\hline Total & 42 & 20 & 30 & 28 & 04 & 14 & 30 & 40 & 44 & 40 & 30 & 42 & 28 & 24 & 28 & 26 & 14 & 16 \\
\hline
\end{tabular}


Table 5. Specifications of an ideal bike.

\begin{tabular}{cc}
\hline & Ideal Bike \\
\hline Wheel size & $20<\times<26$ \\
Battery life & $>500$ \\
Engine position & Rear hub \\
Battery position & Integrated \\
Operating voltage & $>48$ \\
Charging time & $<2.5$ \\
On-board computer & Digital Bluetooth \\
Weight & $<11.9$ \\
Price & $<360$ \\
Supported loads & $<200$ kg \\
Cargo position & 3 \\
Number of wheels & 3 \\
Number of seats & Front and back cargo \\
Compactness & Folding \\
Size & Customized \\
Frame material & Carbon \\
Brake & Hydraulic disc brake \\
Shift & 10 speeds, $3 \times 7$ \\
\hline
\end{tabular}

Summing up the market analysis, we can say that the new bike will have to be autonomous and versatile as a city e-bike, stable and safe as a cargo e-bike, and compact as a folding e-bike.

\subsubsection{Activity Planning}

Before starting the project, we defined a Gantt Plan in which we collected all the activities to be carried out. We set the work period from September to December, a period in which a team of three designers followed the so-called work breakdown structure (WBS). It includes the following macro-phases, also defined in the Gantt chart:

1. Environment analysis

2. Quality function deployment method

3. Benchmarking

4. First design review during the project planning

5. Budget

6. Product architecture

7. Style (stylistic design engineering; SDE)

8. Second design review during the project planning

9. CAD 2D and 3D

10. Prototyping and rendering of product

11. Testing

12. MAP

The Gantt Plan (Figure 3) also establishes the time to be used to end each activity as well as which members of the team take care of which tasks. This ensures the efficiency of each designer and the respect of deadlines.

\subsubsection{Budget: Research and Development Costs}

The evaluation of the research and development budget was made on the basis of a make-or-buy matrix that divides the factory components to be purchased already in stock, and the components that need to be made. The items to buy are a leather saddle, handlebars, cuffs, disc brakes, wheels, drive system, engine, and battery, pedals, spotlight and tires. The elements to be realized are the aluminum frame and the leather cargo, as they are the most characterizing components of the project, and therefore they deserve extra attention in the design. 


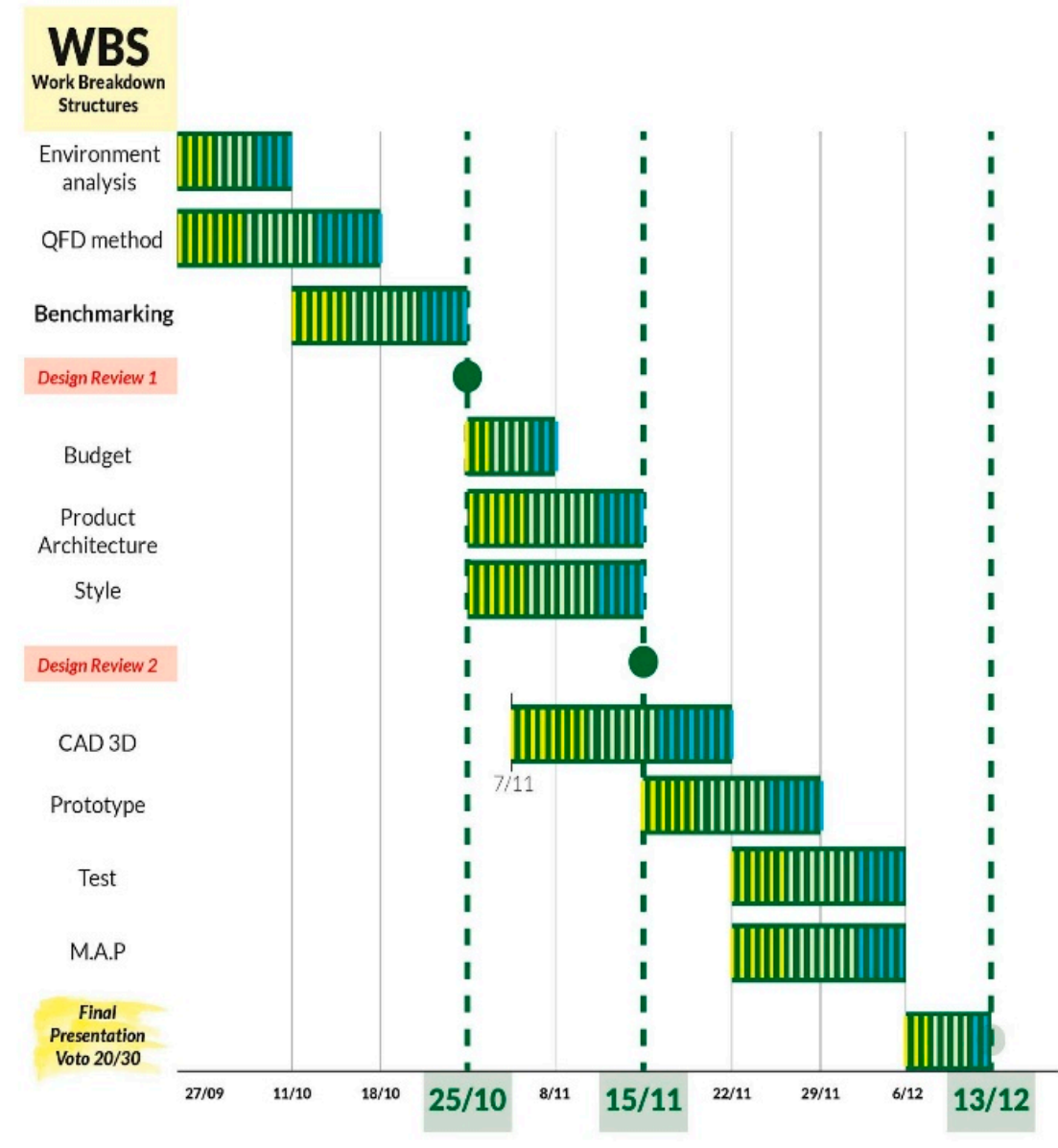

LEGEND:

\author{
Activities \\ done
}

\section{Activities}

to be done

Design
Review
Revisions

Design
Review
Revisions
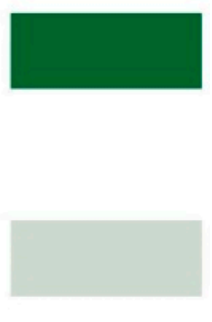

$x x / y y$

Activities

Figure 3. Gantt Plan.

The frame is made of aluminum and is obtained by the deformation of tubular profiles, while the cargo is made of leather or leather with straps for closing. As for the calculation of the budget of the working hours of the staff, a team of three designers, two engineers, two technicians of technologies and processes, and two testers (one male and one female) were hired to work. The two testers are tasked to test the product for the evaluation of pedal assistance, driving comfort, and compactness of the vehicle on urban routes.

The product development path was divided into design, prototyping, and testing. All phases are based on three months of work in which the experts worked eight hours a day for five days a week. The budget evaluation led to the definition of $€ 2847$ for the prototype material and $€ 149,020$ for the R\&D cost (Tables 6 and 7).

\subsubsection{Product Architecture}

From our research on the bicycles that are already on the market, we were able to develop a product architecture that was suitable for our ideal bicycle. Following the IDeS method, we first defined the engine and battery position, and then other technical formal solutions.

An e-bike consists of an electric motor, a battery, handlebar controls, a series of sensors, and an electronic control unit. The nature and arrangement of all these components is variable and determines the type of electric bicycle. The increase in weight of the medium compared to a motorcycle usually varies from a minimum of $3 \mathrm{~kg}$ to a maximum of $6 \mathrm{~kg}$ and requires a solid frame, an adequate braking system, a well-adjusted absorbers, and sturdy tires (Figure 4) [4,5]. 
Table 6. Prototype costs.

\begin{tabular}{cccc}
\hline Prototyping Materials (Euros) & Buy & Make & Total \\
\hline Chassis & & 850 \\
\hline Leather saddle & 40 & \\
\hline Handlebar & 25 & \\
\hline Cuffs & 40 & \\
\hline Brakes & 30 & \\
\hline Front wheel & 60 & \\
\hline Rear wheel & 400 & \\
\hline Cardan transmission & 150 & \\
\hline Engine & 15 & \\
\hline Tubular aluminum profiles & 450 & \\
\hline Battery & 30 & \\
\hline Pedals & 100 & \\
\hline Control panel & 1350 \\
\hline Cargo & 10 & \\
\hline Spotlight & 10 & \\
\hline Bell & 17 & \\
\hline Saddle bag & 60 & \\
\hline Fender & & \\
\hline Tires & & \\
\hline
\end{tabular}

Table 7. Budget R\&D.

\begin{tabular}{cccccc}
\hline Tasks & 3 Designers & 2 Engineers & 2 Technicians & 2 Testers & Total \\
\hline $\begin{array}{c}\text { Design } \\
(3 \text { months })\end{array}$ & 480 & 480 & & & \\
\hline $\begin{array}{c}\text { Prototyping } \\
(3 \text { months })\end{array}$ & 480 & 480 & 480 & 360 & \\
\hline $\begin{array}{c}\text { Testing } \\
(3 \text { months })\end{array}$ & 480 & 480 & 64 & 240 & \\
\hline $\begin{array}{c}\text { Optimization } \\
(3 \text { months })\end{array}$ & 1140 & 1760 & 480 & 1120 & 15 \\
\hline Total hours & 40 & 40 & 20 & 10,560 & 149,020 \\
\hline Cost per hour & 47,660 & 68,400 & 22,400 & \\
\hline
\end{tabular}

1. Engine

The engine can be immediately distinguished from the position on the e-bike, and currently there are three main types (Figure 5):

- $\quad$ engine in the hub of the front or rear wheel, known as engine to the hub or a hub motor;

- $\quad$ engine under or in place of the center movement box, known as the central motor, also called a mid-drive motor;

- motor in the vicinity of the front or rear tire, known as the roller or clutch engine, also called a roll drive motor or friction drive motor. 


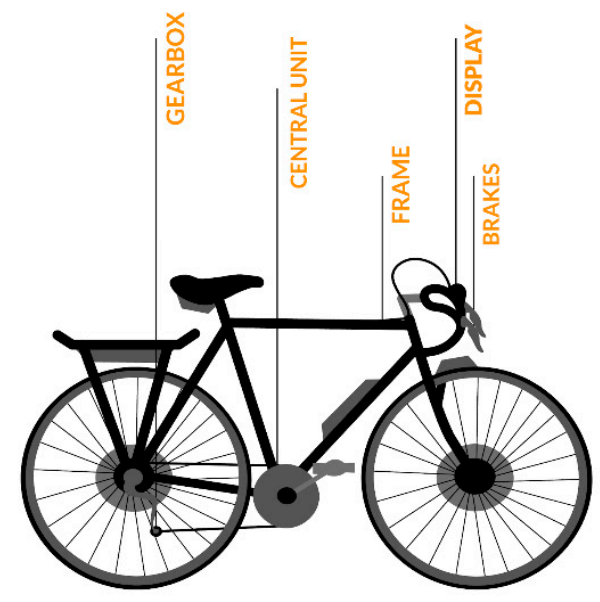

Figure 4. Architecture of the product of an electric bike.
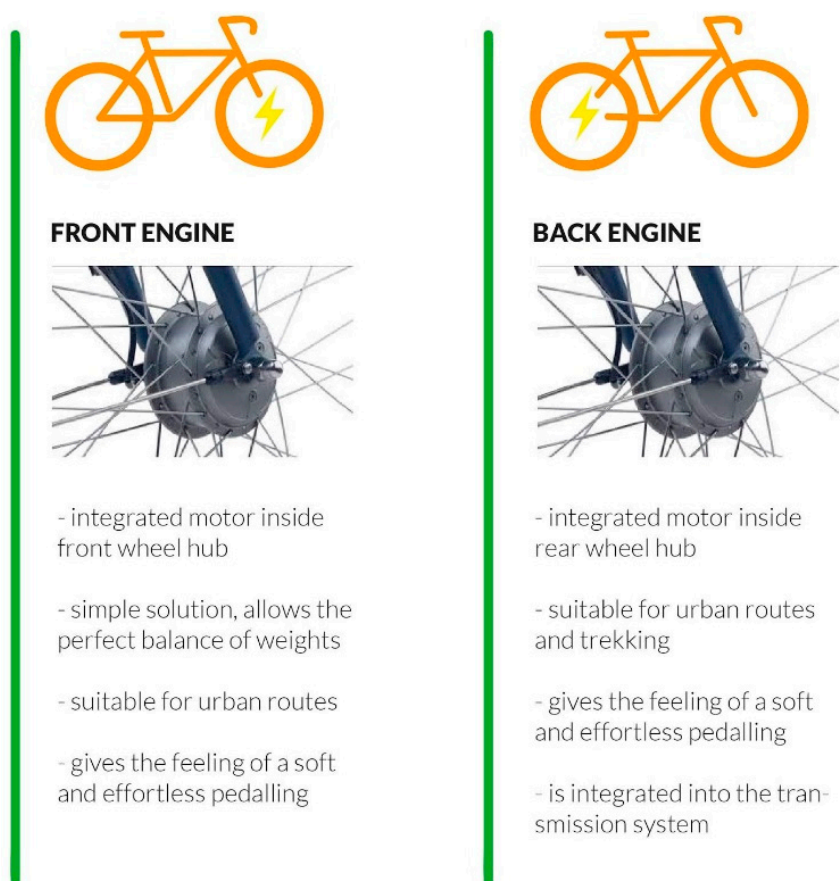

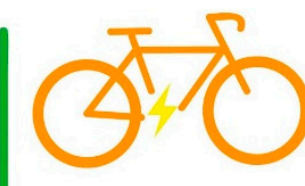

CENTRAL ENGINE

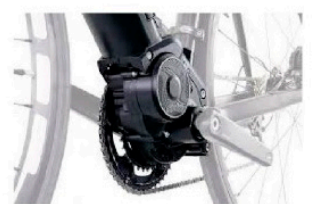

- highly technological configuration

- ensures the supply of energy in proportion to the effort impressed on the pedal

up to $30 \%$ gradients

- suitable for mountain bike and trekking e-bike

Figure 5. Types of engine layout.

\section{Battery}

The battery is the heart of the e-bike, as this is what gives the bike its power. We can find it in different places of the bike, but the location in this case does not provide any information about its internal characteristics. In a nice casing, one can hide a low- or high-quality battery and vice versa. The following are possible cases of battery placement (Figure 6) [5]:

- $\quad$ Battery is placed in the location normally reserved for a water bottle holder; the inside is a container integrated with graphics and frame lines to harmonize the aesthetics as much as possible. It is the most classic position, and sometimes it is hidden inside a fake canteen.

- $\quad$ Battery is placed in the rear rack, inserted inside a housing that allows users to load weights on the luggage rack without burdening the battery itself.

- $\quad$ Battery is placed under the saddle. It can be found in a rigid box or in a generally small bag. 
- $\quad$ Battery is placed on the handlebars. This is the rarest case because if it is heavy it will seriously affect the maneuverability of the bike.

- Battery is integrated into the chassis. In this case, the battery is located inside the chassis or in the middle of the chassis as a carrier.

- $\quad$ Battery is in the backpack. The battery is inserted in a special pocket of the backpack that keeps it as close as possible to the back to minimize the load on the shoulders.

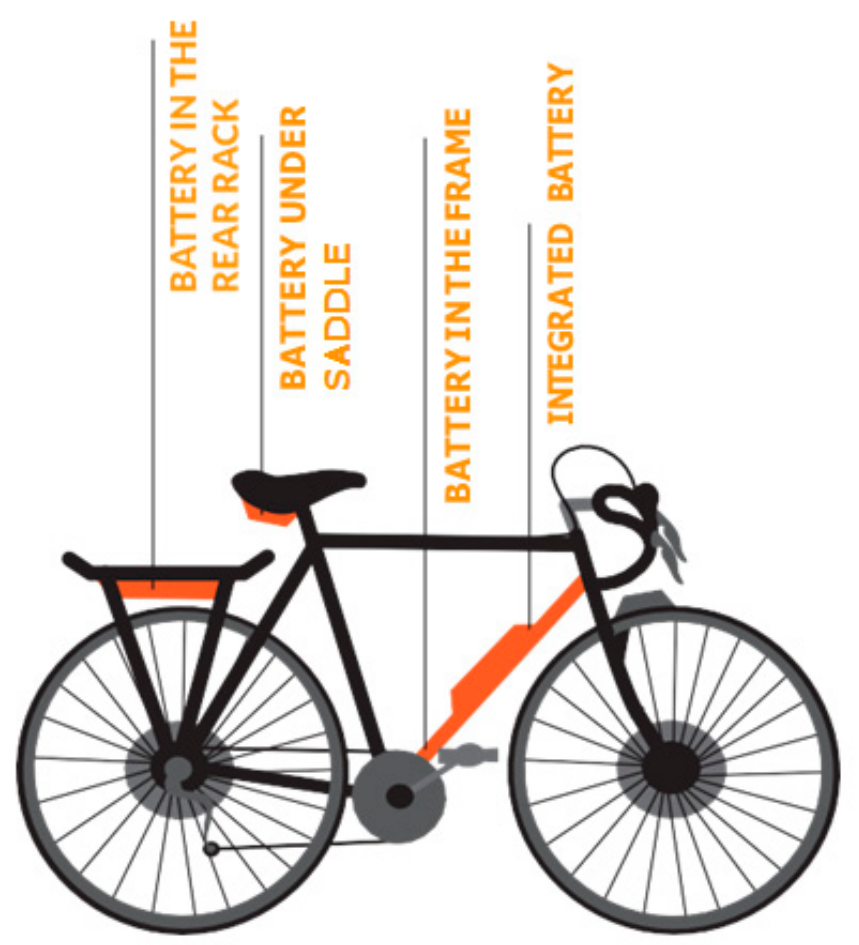

Figure 6. Types of battery layout.

\section{Architecture of the new product}

The transmission system is entrusted to the drivetrain, which represents the most significant innovation in bike transmissions in recent years, if not decades. With the elimination of the chain, gearbox, and derailleur, this system is based on a gimbal, i.e., a shaft that transmits the pedal force from the crown (single) to the sprockets, where there are 13 in all. The cardan uses bearings to transfer the power, which happens with a reduction of $49 \%$ of the friction compared to the traditional system with sprockets, crowns, and chain [6].

This solution, used for the first time by Euro-bike, allows for 13 different ratios, obtained by moving the rear gear of the cardan on the various sprockets of the cassette. As far as the transmission concerned, the cardan is the optimal solution when the engine is arranged lengthwise in the frame. Specifically, the cardanic transmission "takes" the motion from the crankshaft and transfers it directly to the rear wheel. For this reason, it integrates perfectly with the motor to the hub. The system requires a specific frame that can accommodate the gimbal, and the hub does not require any special arrangements at all and is integrated into the transmission system.

The choice of engine position derives from the study that was done using the QFD method. Among the bikes that achieved a higher number of tops in benchmarking, there is the Moop Bike Hybrid city and the Pedego stretch cargo dual drive. Both products have a hub engine; in fact, they are high-performing bikes. Using the what/how matrix we identified the profile of the ideal bike, which has an engine at the rear hub, not a central engine. 
According to the design of the supporting structure, it was essential to consider the position of the battery. Given the product architecture of our bike and the shape of the frame, we opted for the battery in the saddle, as this is space-saving and less invasive.

\subsubsection{Stylistic Design Engineering (SDE)}

We analyzed different types of styles and made sketches for each of them. In this way, we could choose the most suitable design among several: (1) natural (Figure 7), characterized by organic lines but solid at the same time; (2) retro (Figure 8), which recalls the classic bicycles of the boom years, with highly vintage accessories and a leather trunk, as if it were a suitcase; (3) advanced (Figure 9), which is characterized by futuristic lines, and the whole is reduced to the use of bends both in the rods and in the circular joints; and (4) stone (Figure 10), a more aggressive style that relies on the exaggeration of the lines, to the point where they give origin to appendices of the structure, as in the case of the very accentuated fender.

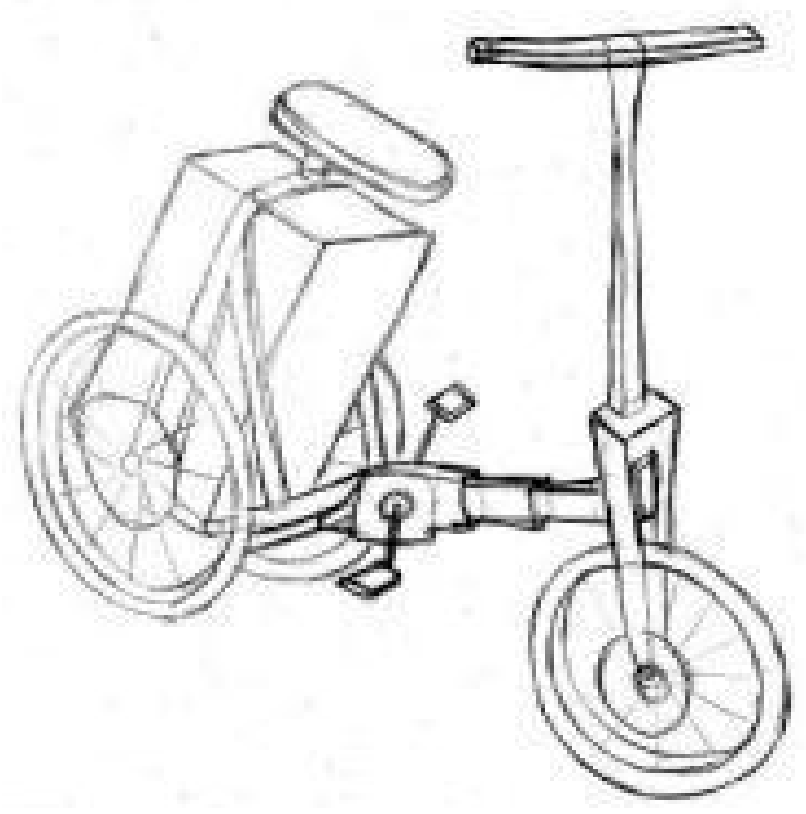

Figure 7. Natural style.
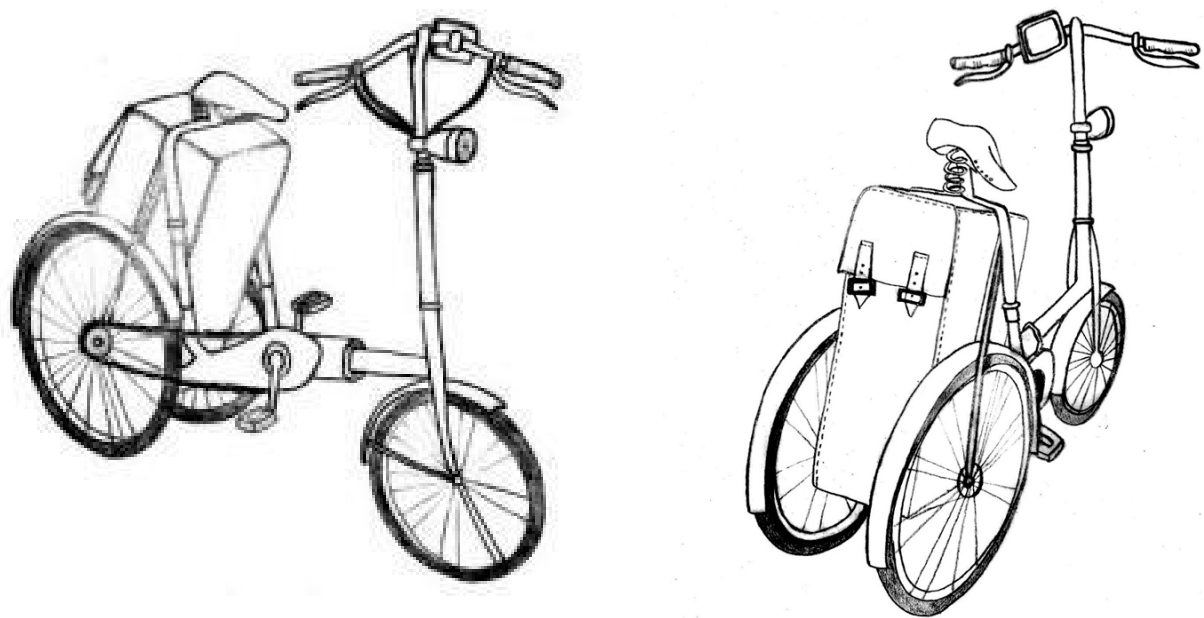

Figure 8. Retro style. 


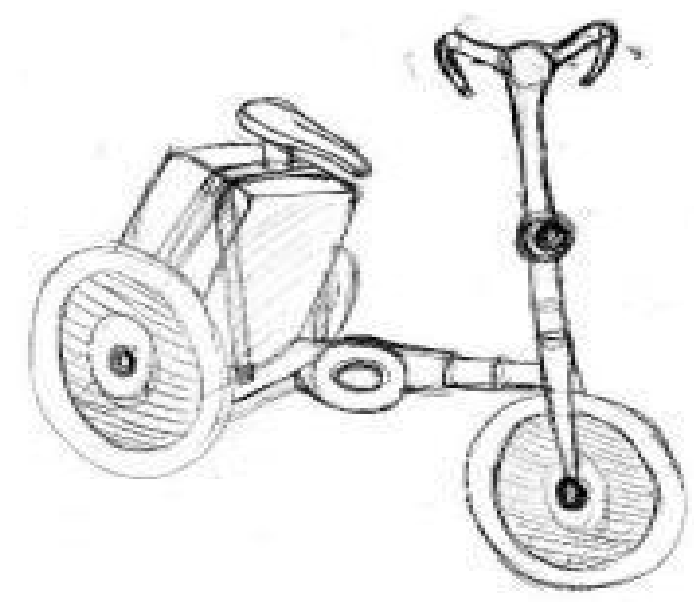

Figure 9. Advanced style.
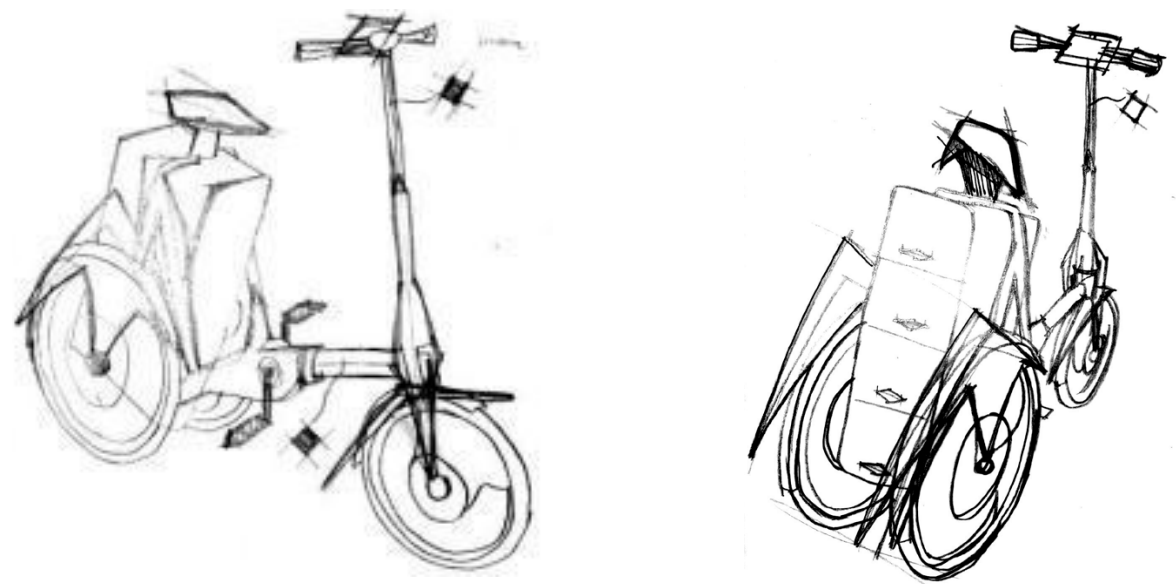

Figure 10. Stone style.

In light of the sketches, we carried out a reflection on the archetypes of the product "bicycle". We looked in the literature for examples that gave an iconic and interesting image of the bike, and in the end we decided to analyze two fundamental models, i.e., the Atala model Piccadilly and the Graziella model Cinzia (Figures 11 and 12).
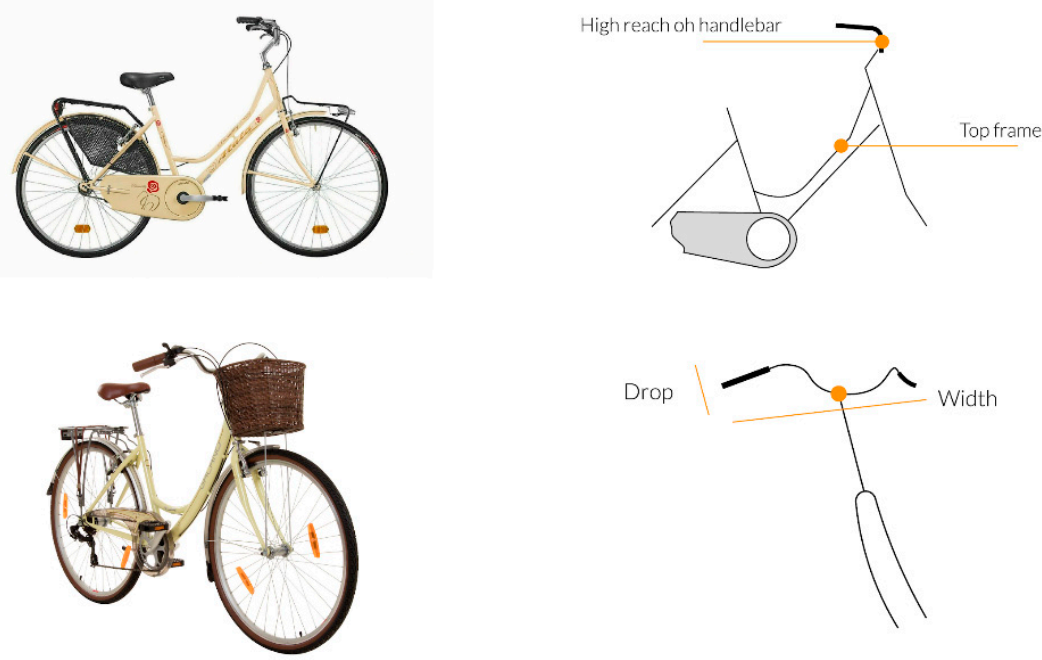

Figure 11. Stylistic references for the retro style—the Atala Piccadilly. 

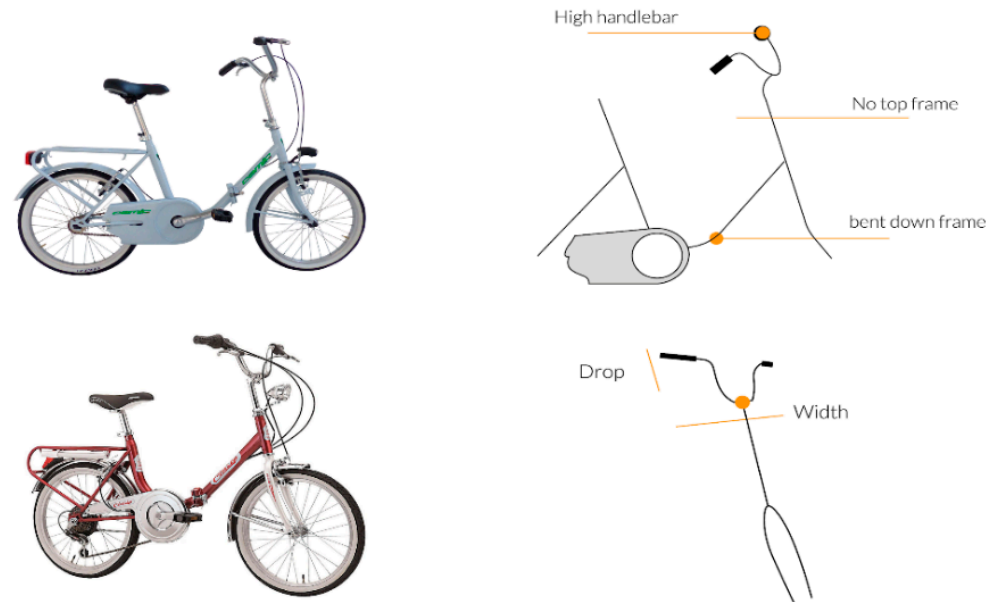

Figure 12. Stylistic references for the retro style-the Graziella Cinzia.

\subsection{Product Improvement}

In product development, we applied all the theory that we carried out in the previous phases and moved onto practice. This is how we defined the technical drawings and the more engineering aspects of our bicycle.

\subsubsection{Design Engineering}

As for dimensions, the bike has a height between 756 and $826 \mathrm{~mm}$ because of the gas spring that secures the folding bike. Because of the gas spring used, there is a range of adjustments for the length of the frame. The aluminum frame has a dimension between 687 and $1035 \mathrm{~mm}$, based on the activity carried out by the user. In this phase, 2D drawings (i.e., orthogonal projections) of the bike were made (Figure 13).
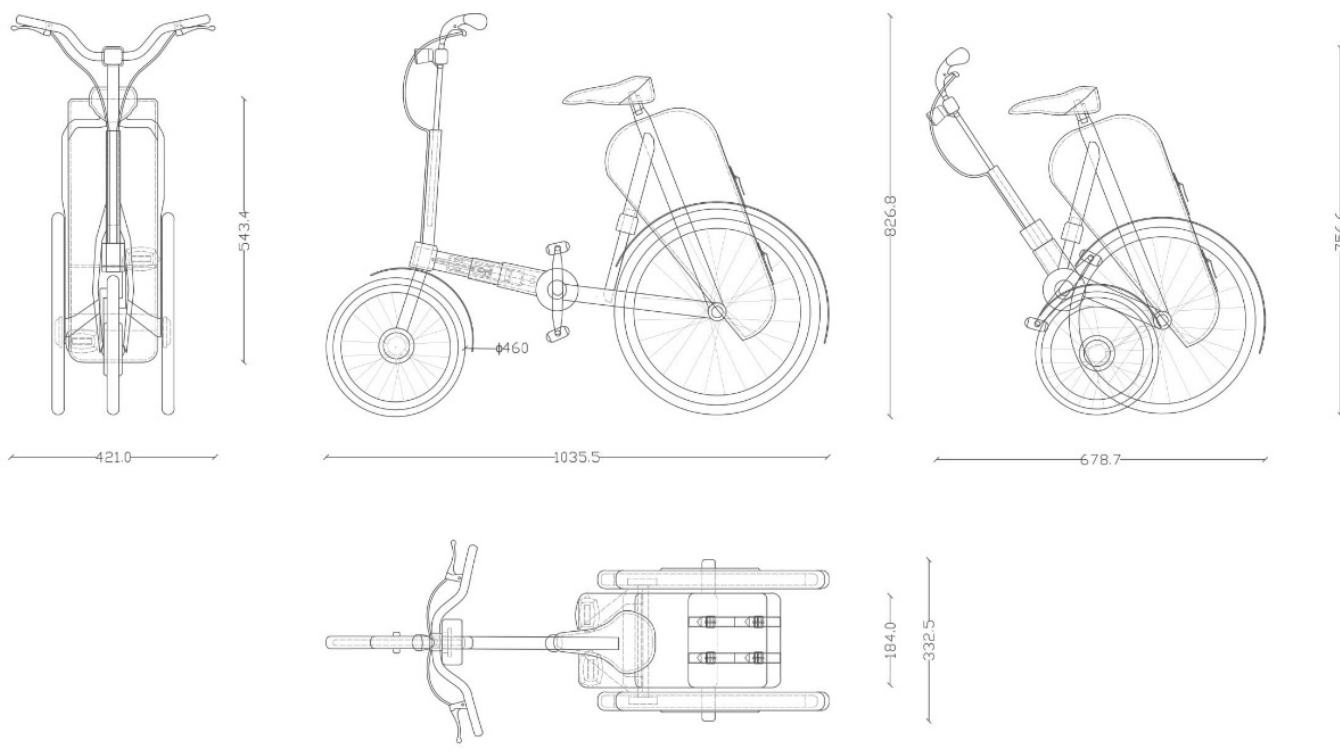

Figure 13. Design engineering: orthogonal projections.

Subsequently, the following definitive materials were chosen:

- Frame: Anodized aluminum

- Coat: Blue paint

- Cargo: Natural leather

- Saddle: Natural leather

- Handlebar cuffs: Natural leather 
As regards the transmission, we chose not to insert the chain kit. Instead, a cardanic transmission was chosen (Figure 14), where the transfer of motion of the cardan joint occurs due to the incidence in a point of two rotation axes. The decision is due to a number of advantages brought about by this type of transmission including minimal maintenance, easy cleaning, no noise, smaller footprint, and more pleasing aesthetics [7-11].
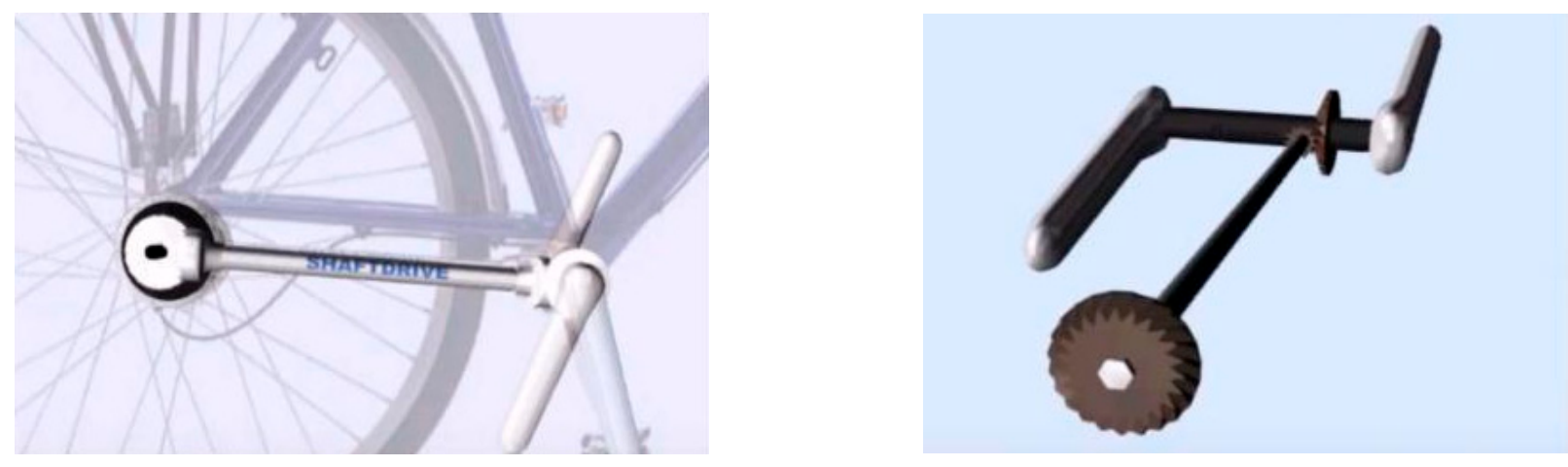

Figure 14. Functioning of the cardanic transmission.

Concerning the range of the length of the bike, the main innovation of the product is the telescopic frame. To solve the problem of handling and folding the bike, we used a gas piston to reduce the dimensions and to close the bike as a trolley.

We opted for this system because it is a solution that allows the user to close the bike without lowering it. Other mechanical systems work only if the user gets off the bike and lowers it to close the levers of the frame. With a gas spring, the bike can also be closed with the user staying in the saddle and pulling the bike towards them.

The gas spring is composed of a steel cylinder containing pressurized gas (nitrogen) and a stem that flows into the cylinder itself through a sealing ring. The pressurized gas from the stem entry returns a thrust, behaving like a spring (Figure 15).
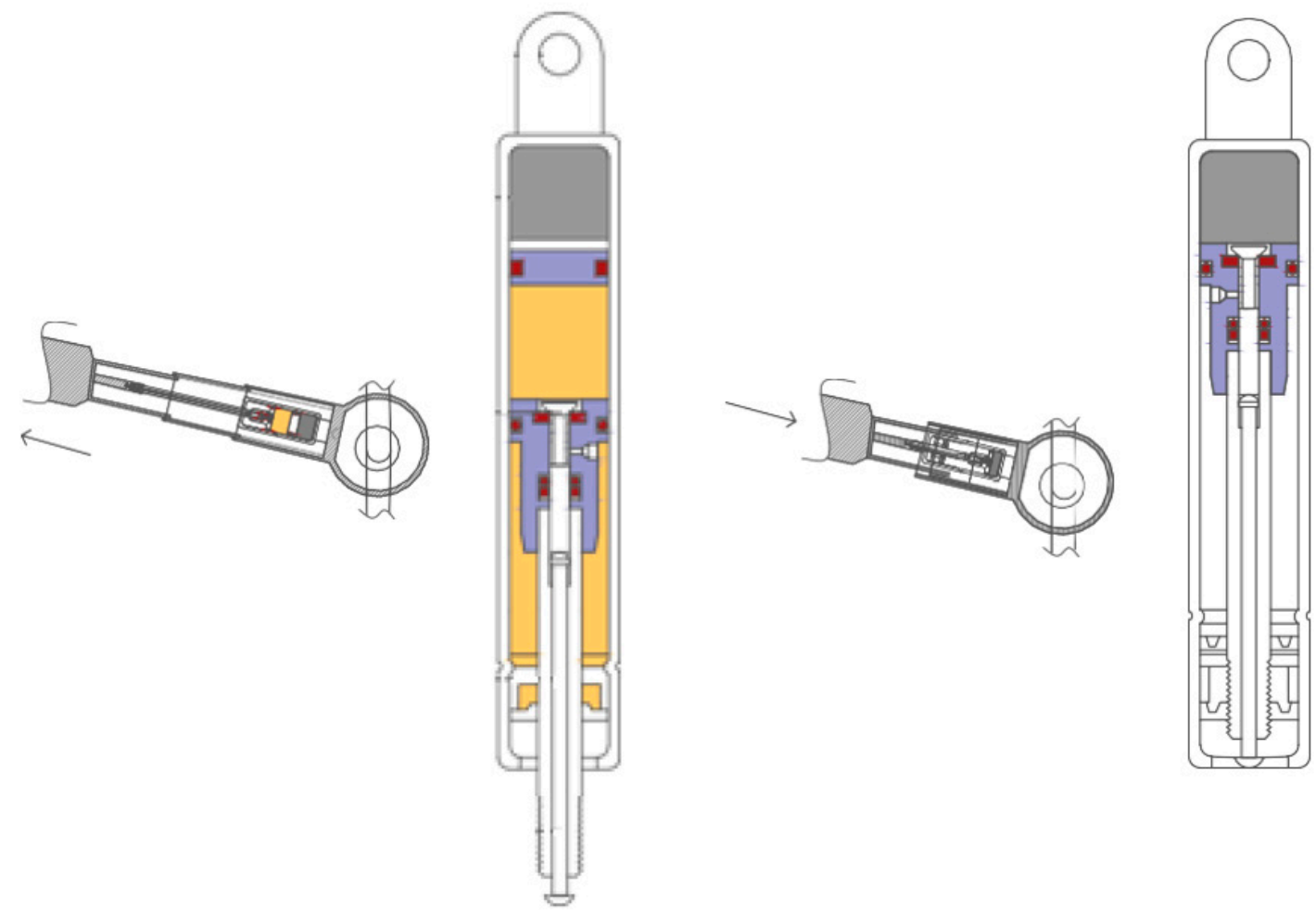

Figure 15. Functioning of a gas spring and positioning in the vehicle. 
Compared to traditional mechanical springs (whether helical, cup, or rubber), the gas springs have an almost flat force curve, even for very long runs. They are used in all those cases where it is necessary to obtain a thrust proportionate to the weight to be lifted or moved, or to counterbalance the lifting of mobile and heavy equipment.

The most common applications are visible on car doors, on industrial machinery protection cases, on furniture doors, on medical and fitness equipment, on tents and motorized covers, on attic skylight windows with an opening, and inside the supermarket stalls and butchers. A certain amount of oil is introduced in the gas spring cylinder; in addition to ensuring the lubrication of the seals and to interposing between the piston and its guide, the oil performs a slowing action in the extension phase of the stem, providing a smoother movement without startling.

The thrust of a gas spring is determined by the pressure that the nitrogen, placed in the cylindrical body, exerts on the section of the stem. It is possible to assemble stems of more or less sections with bodies of appropriate volume, to act on the gas inlet pressure, to adjust the passages present on the piston or to add more oil; in addition to the desired forces, various operating configurations of the gas spring can be obtained so as to satisfy the wide needs of the users.

A gas spring was chosen in order to have a more intuitive usability and a simpler interaction for the user. In fact, to close the bicycle it is not necessary to carry out many movements, such as bending or unscrewing bolts. The only necessary action is to push the handlebars, and the bicycle will close naturally. In order to achieve this, when assembling the spring in the frame, it is calibrated to respond to a certain Newton range [12-16].

\subsubsection{Prototyping and Rendering of Product}

In order to make a 3D CAD rendering, we used a software called Rhinoceros, a NURBS surface modeler. Once we realized the three-dimensional model, we applied the correct textures and materials to have a simulation of the real product through rendering technology (Figures 16-21). Finally, in order to verify the product model, we created a prototype in scale 1:5 using 3D printing technology (Figures 22-24).

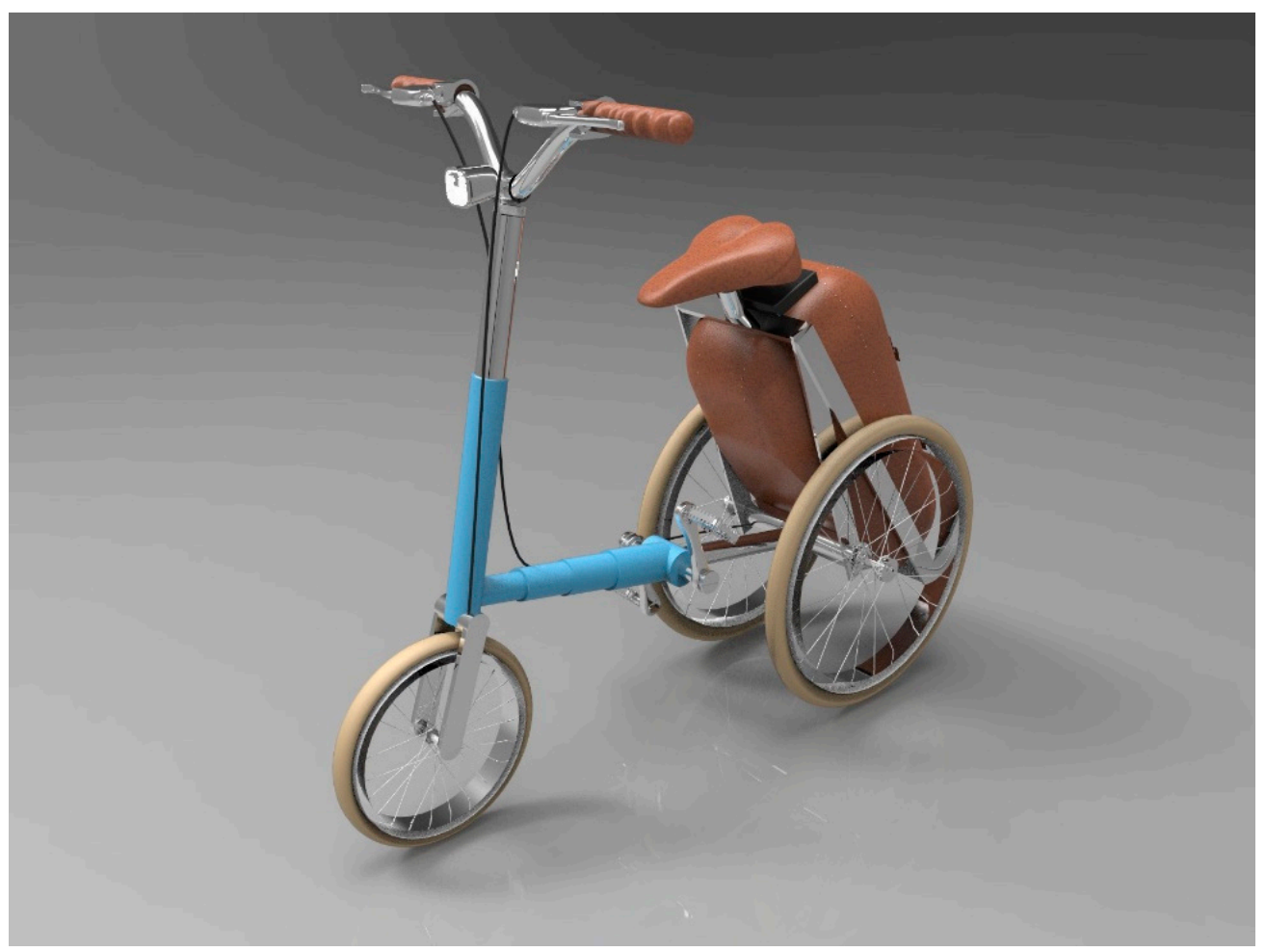

Figure 16. 3D model and rendering. 


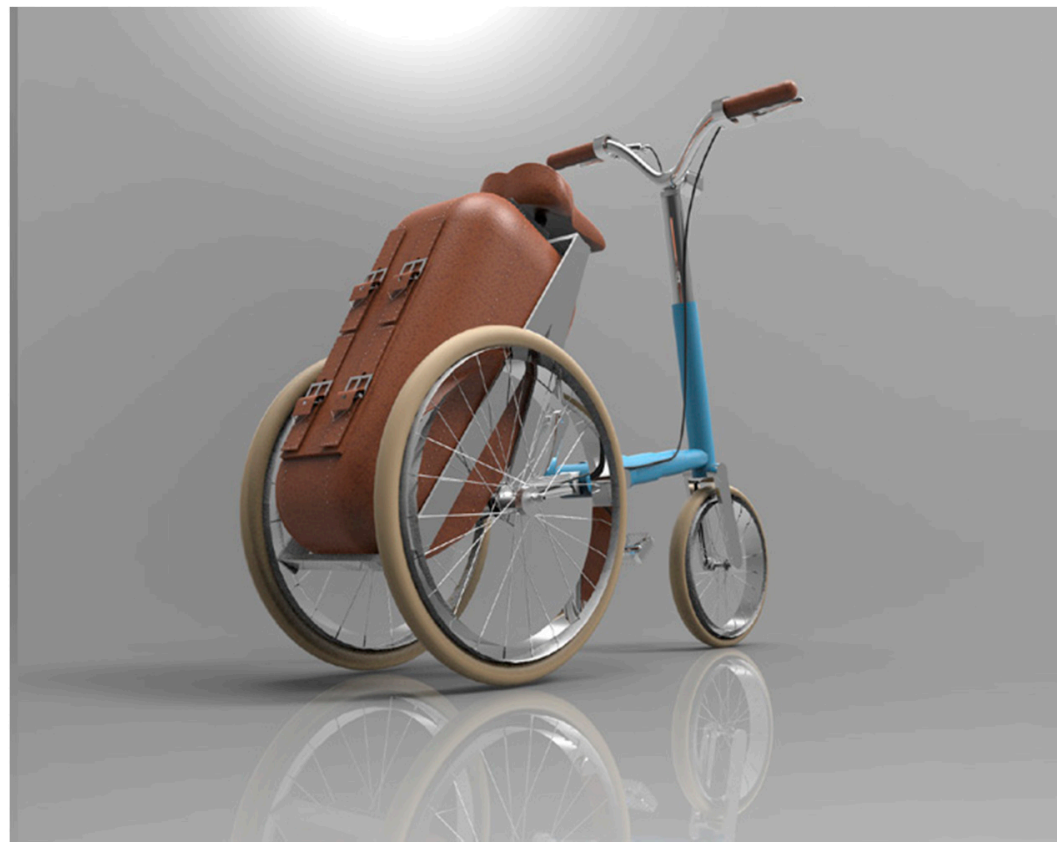

Figure 17. 3D model and rendering.
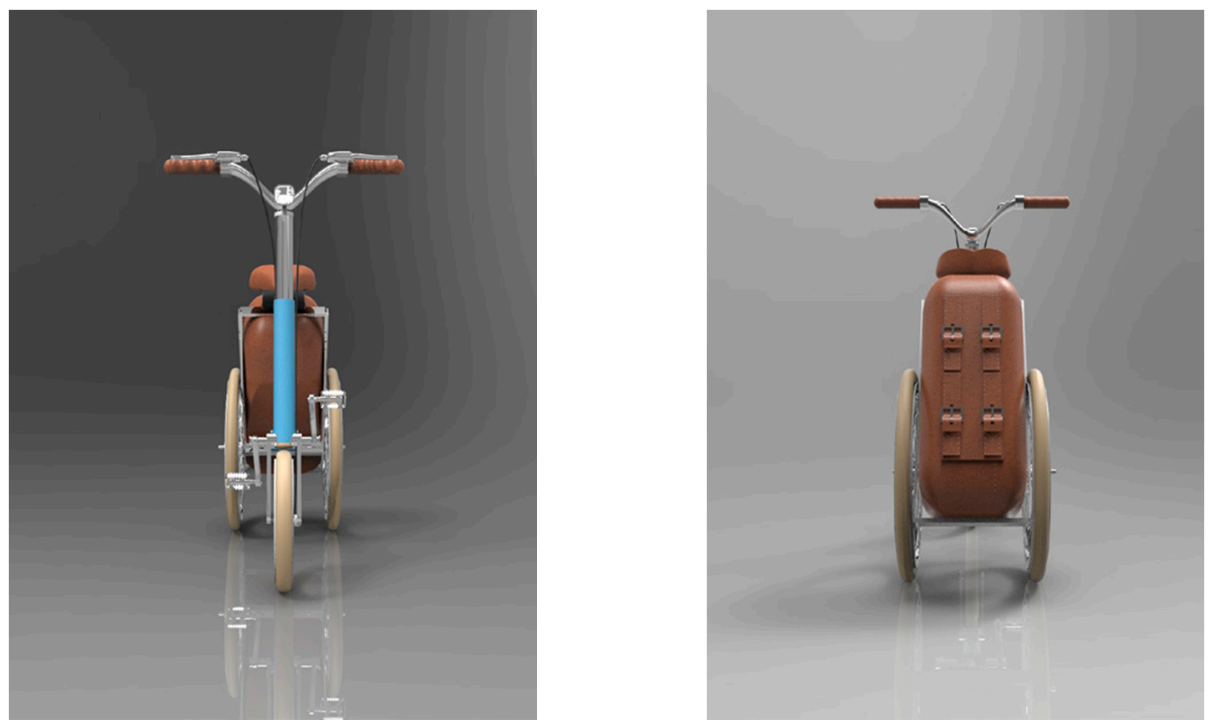

Figure 18. 3D model and rendering.
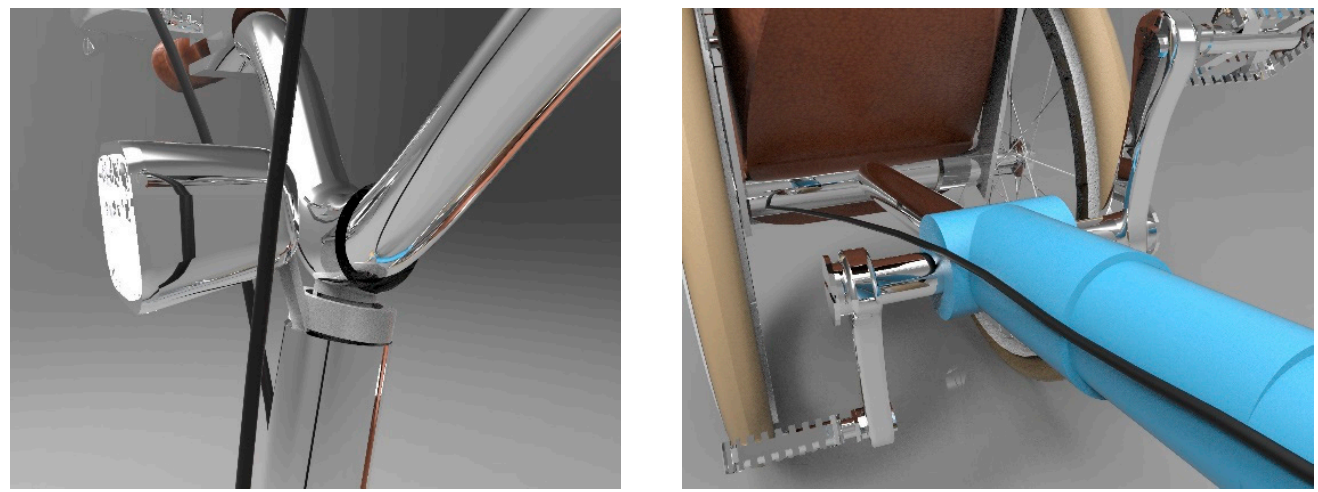

Figure 19. 3D model and rendering. 


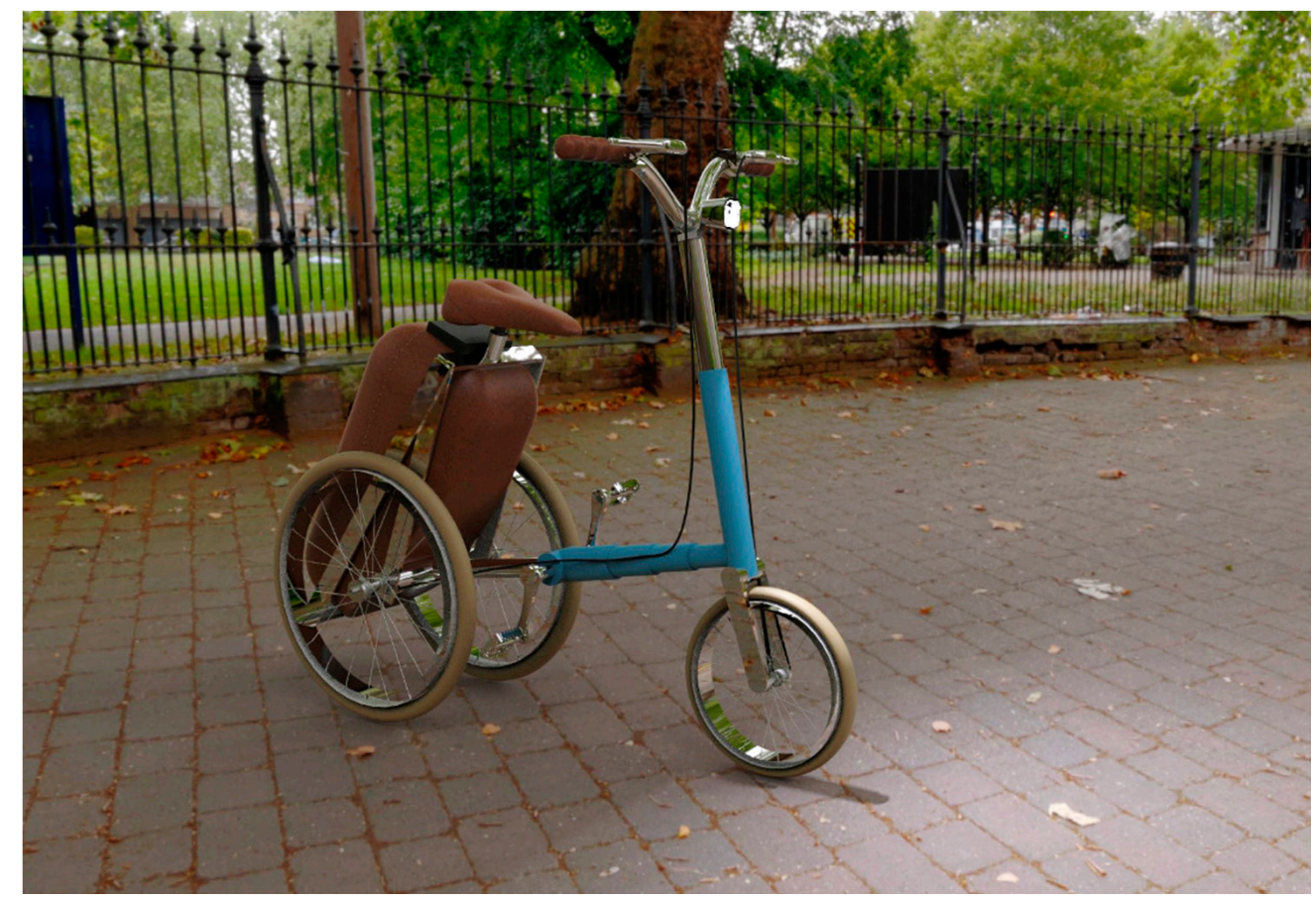

Figure 20. 3D model and rendering.

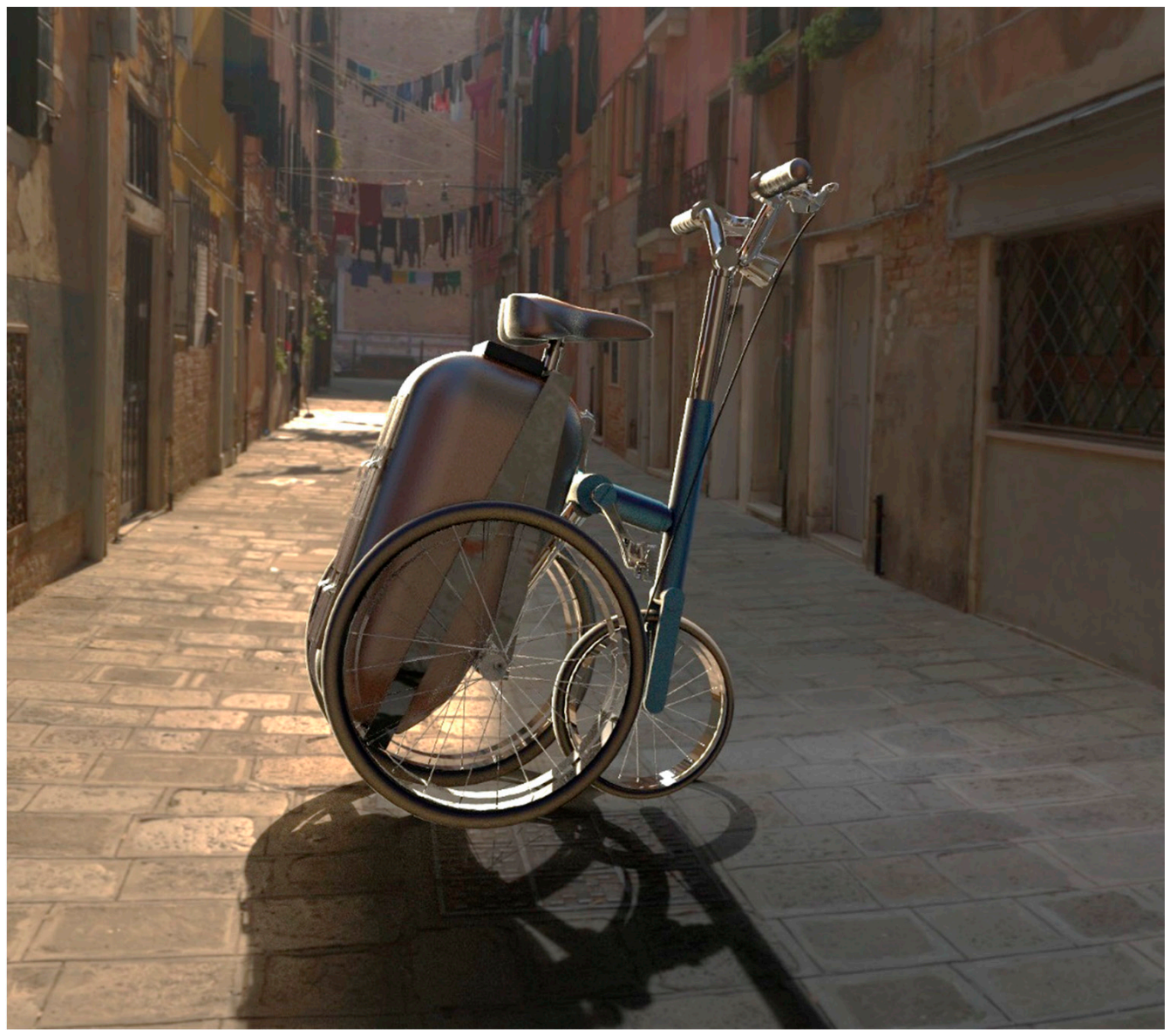

Figure 21. 3D model and rendering. 


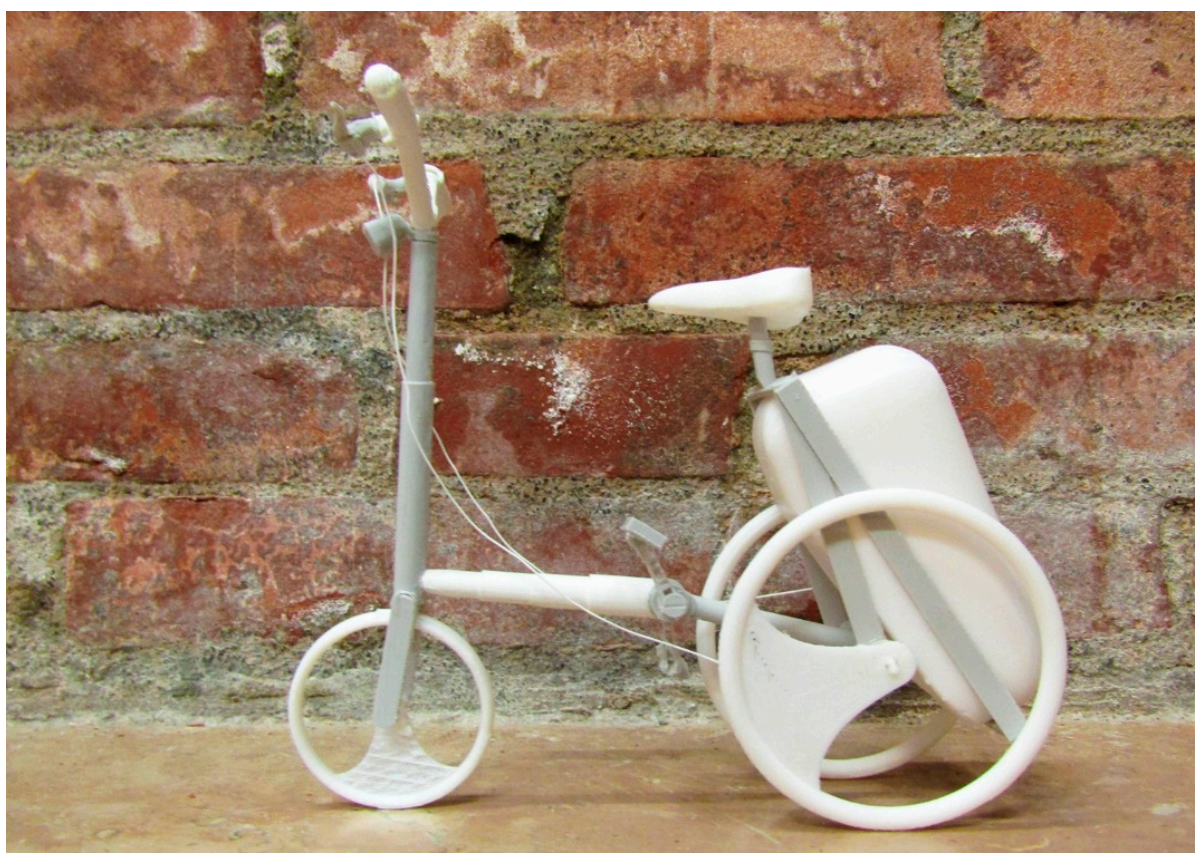

Figure 22. 3D printing bike.
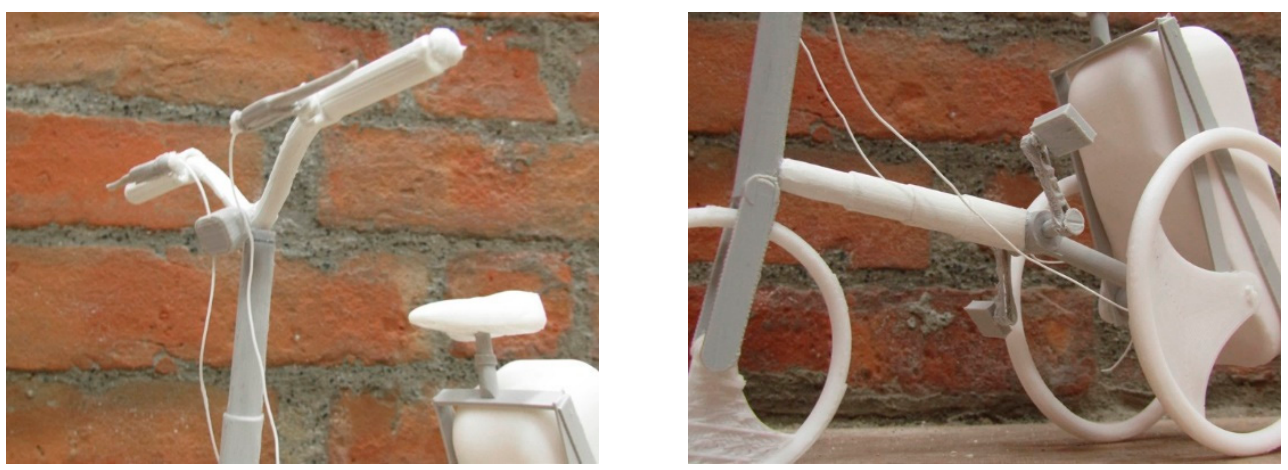

Figure 23. 3D printing bike.

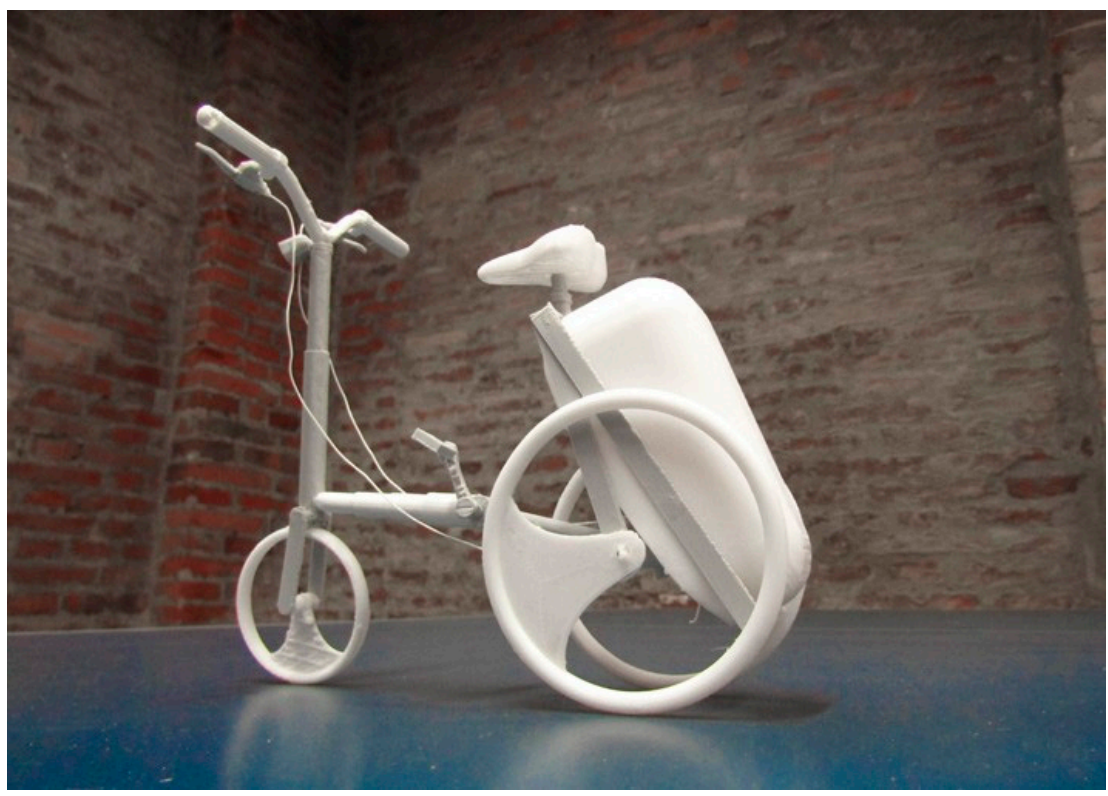

Figure 24. 3D printing bike. 


\subsubsection{Testing}

Using the solid modelling program Inventor, the frame was redesigned to study the static condition and loads applied. On the upper part of the frame, a force equal to three times the estimated load of an average person $(90 \mathrm{~kg})$ was applied to the saddle, and so the structure was studied with $270 \mathrm{~kg}$ of load. In addition, the stress resulting from the leather cargo, which has a capacity of approximately $58 \mathrm{~L}$, was added [17-20].

Constraints on structure and materials were then defined, which in our case is anodized aluminum. Once the calculation program was run, it emerged that the stress was exaggerated with respect to the material and the assumed dimensions; in fact, the deformation was a beam with an axial applied load. One possible solution to the problem is to change the assigned material and sizes. As a matter of fact, by assigning the stainless steel and changing the size of the shaft to $1.75 \mathrm{~cm}$, the deformation is much lower, and at the extremes, the stress is less concentrated (Figure 25).

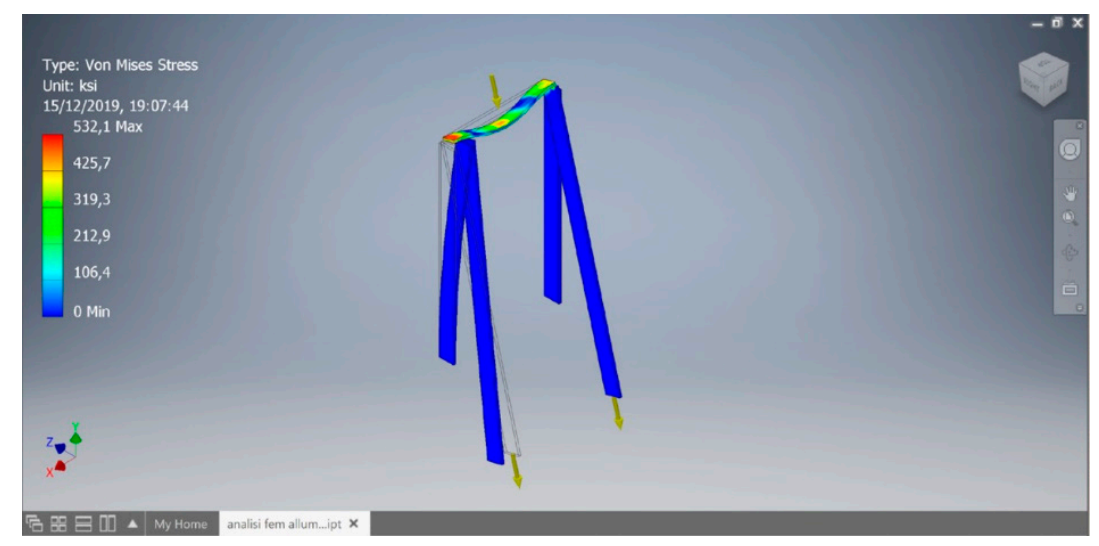

Figure 25. Messa a punto (MAP) stress analysis.

\section{Results and Future Development}

From the matrices, the findings show that the bike should be compact, light, versatile, transportable, accessorized, economical, and stable. Furthermore, new features were added due to the use of the motion system, but there is more innovation: The bike is the first on the market with both cargo and the possibility to be closed like a foldable bike.

A prototype in scale 1:1 is in thought for the future to be tested by regular users to find out whether there are any problems. Alterations to the project can be applied to respond to the results of these tests.

Realizing a real model in scale 1:1, we verified whether it is to realize a working and realizable product, following the IDeS method. Because of this verification, we can be sure that the method is valid for conceiving a new product based on analytical studies on other existing models. In the future, we hope to be able to apply the IDeS method for many other equally valid products [21-24].

\section{Managerial Insight}

In the present work, IDeS demonstrated how it is possible to solve problems linked to the structuration and the implementation of a new project, which can also be considered as starting "from a clean sheet". Therefore, in organizing all the phases, it is possible to fill them in with more or less skilled designers and engineers in order to reach the goal to have an innovative solution for a new product at the end.

Looking now at what Richard Daft [25] said in 2010, namely that "the core of the organization is about the product and its conception", we can say that IDeS can be considered the logical link between the technical and the management phases inside a company. In Figure 26, we can see that the main pillars of the organization must revolve around the generation of a new product, and three departments must be considered, namely one for marketing, one on $\mathrm{R} \& \mathrm{D}$, and the last one about production. 


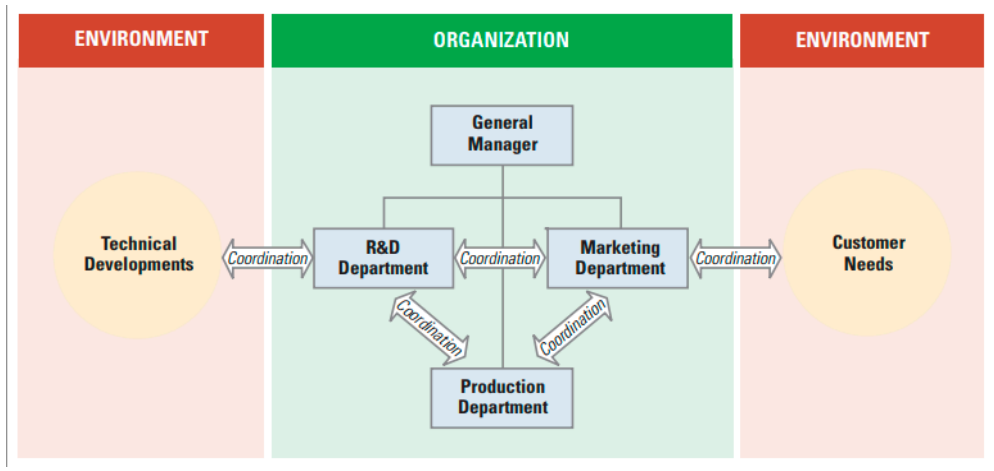

Figure 26. Richard Daft's company organization concept (2010).

This idea is exactly the same for the IDeS approach. Many aspects of the IDeS design methodology matches Daft's model, as it can be seen in Figure 27.

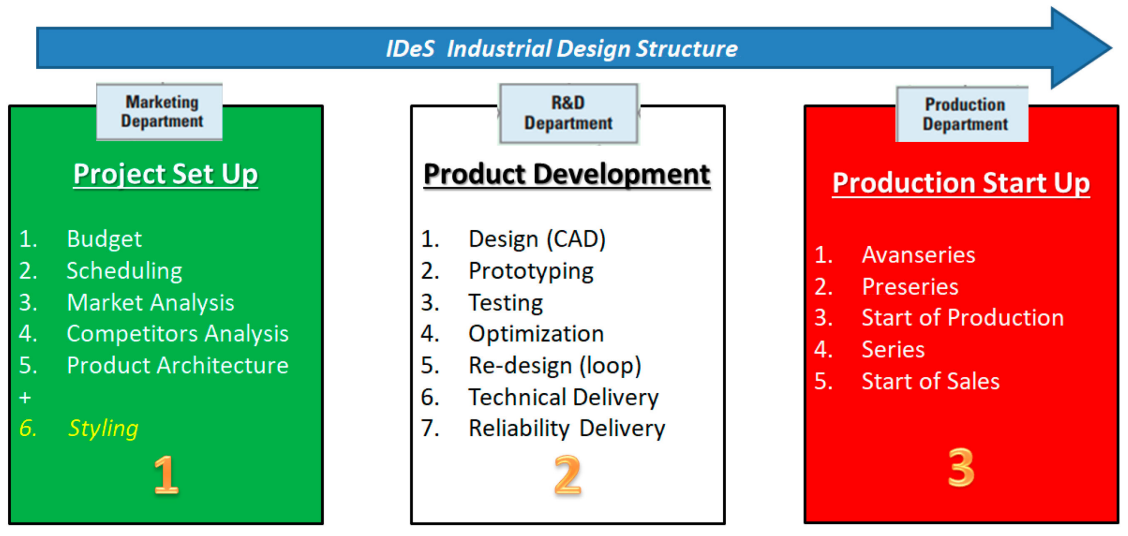

Figure 27. Daft's idea of company organization matching aspects of IDeS.

Moreover, in the Industrial Engineering and Organization Management (IEOM) Conference at Harare in 2020, Frizziero illustrated that it is possible for human resources (HR) to better understand where to collocate the right skills. This properly follows the IDeS structure, as illustrated in Figures 28 and 29.

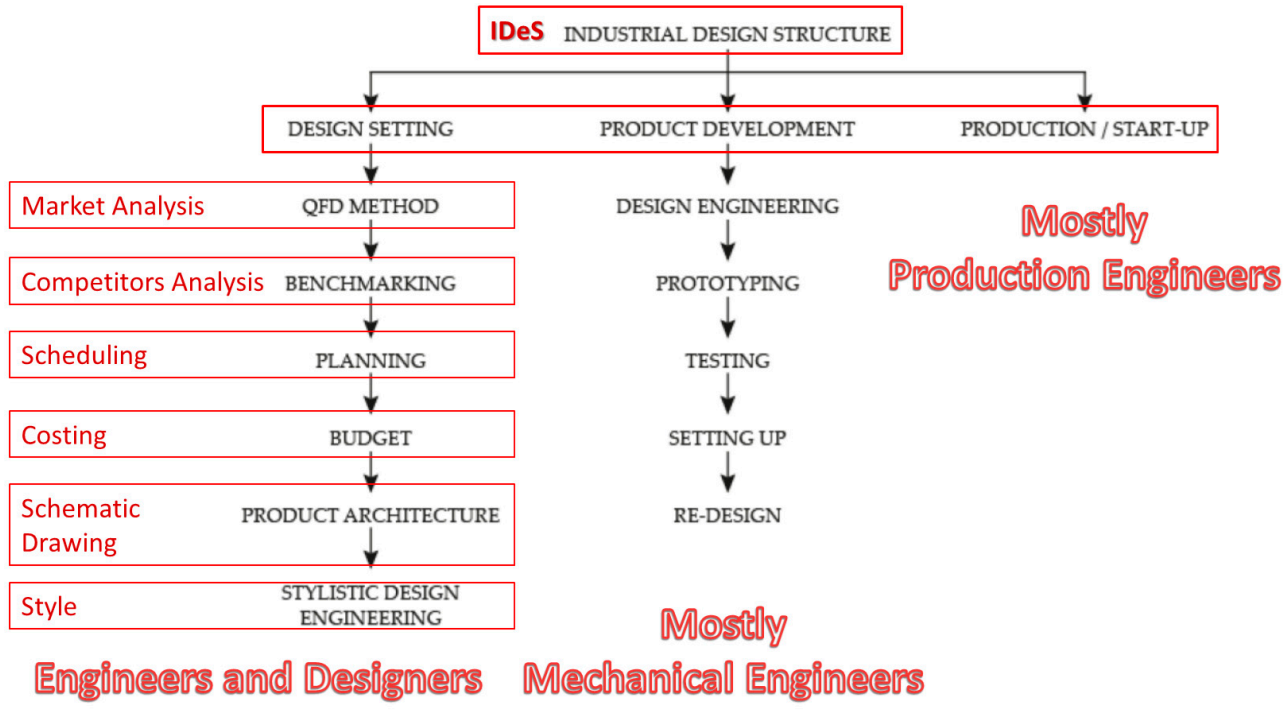

Figure 28. IDeS vs. human resources. 

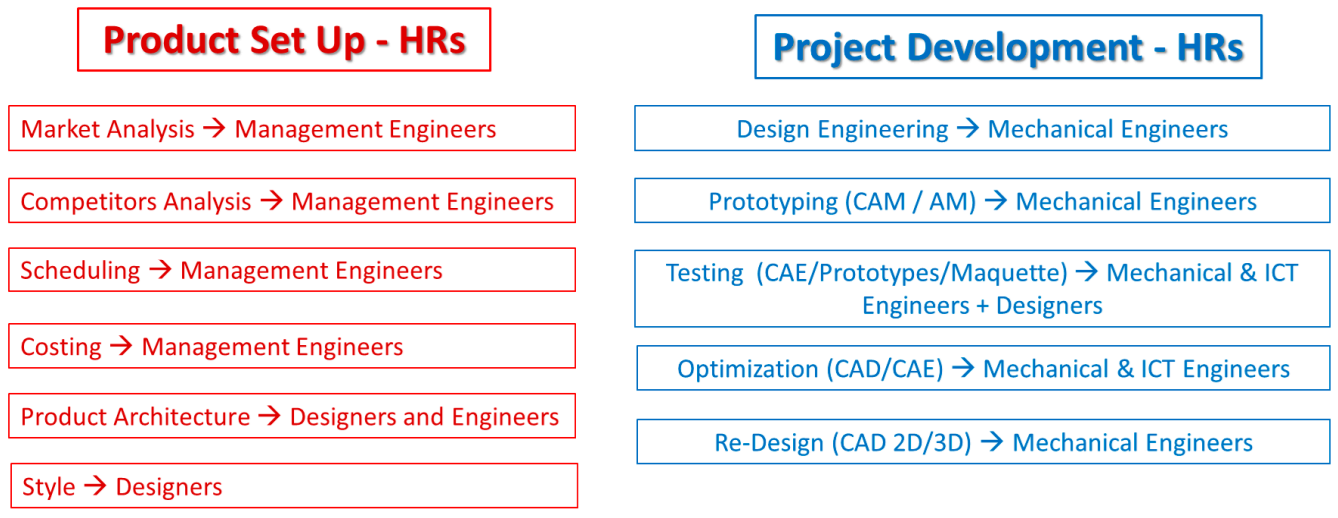

Figure 29. IDeS vs. specific skills for HR.

In particular, it can be noticed (Frizziero, 2020, IEOM, Harare, Zimbabwe) [26] that HR should hire mostly designers and management engineers for the product setup phase positions, and for the product development phase positions, HR should hire mostly mechanical and ICT engineers. Finally, HR should hire mostly production engineering for the production startup phase positions.

\section{Conclusions}

The present work demonstrates the efficiency of the new methodology, i.e., industrial design structure (IDeS), which was developed and applied in the presented case study. Our work validated the possibility of integration between this complete industrial method and the leading approach, which is QFD. Through IDeS, it is possible to organize both the design process and company organization. IDeS is a road map through which unskilled designers can also implement a new project easily and systematically. IDeS includes management phases, technical phases, and aesthetic phases. It is the most complete way to design an entire industrial project.

Regarding the project obtained, it was possible to create a new product that was innovative on the market in terms of usability and compactness. Among its main features, the key ones that stand out include its dual function, in that in can be opened as a classic bicycle and closed as a transportable handlebar-equipped trolley. It is designed in a way where users can choose how to use it according to their activities in the city. A large cargo is included in order to help them carry large loads, whether the e-bike is closed or open. Many requirements were met in the project. For example, regarding compactness, a gas spring was inserted in the frame in order to allow the bicycle to close and to make it more easily transportable. As regards the usability, we considered how to develop a new type of habit that includes ecological and healthy awareness. For this reason, a cargo was designed so that it can fulfil all the normal needs of daily working life.

A compromise was substantially achieved between comfort and sustainability, as we hoped that with our project, we can implement an opening towards new scenarios of everyday city life, developed around an idea of sustainability and freedom.

Author Contributions: Conceptualization, L.F.; methodology, L.F. and G.D.; software, A.L.; formal analysis, A.A. and D.R.; investigation, G.D.; resources, M.G.P., M.L.T. and I.G.; data curation, D.R, A.A., L.F.; writing—original draft preparation, M.G.P., M.L.T. and I.G.; writing—review and editing, L.F.; supervision, L.F., G.D., A.L. All authors have read and agreed to the published version of the manuscript.

Funding: This research received no external funding.

Conflicts of Interest: The authors declare no conflict of interest. 


\section{References}

1. Caligiana, G.; Liverani, A.; Francia, D.; Frizziero, L.; Donnici, G. Integrating QFD and TRIZ for innovative design. J. Adv. Mech. Des. Syst. Manuf. 2017, 11, JAMDSM0015. [CrossRef]

2. Di Stefano, A. La Bikeconomics in Italia Secondo Legambiente: 6,2 Miliardi L'anno, ma Potrebbero Superare i 22. Available online: https: / /impact.startupitalia.eu/2018/10/24/legambiente-abici-mobilita-italia/ (accessed on 25 October 2019).

3. BiciLive, Tutto sulla bicicletta elettrica a pedalata assistita; Com'è fatta una bicicletta elettrica? Tutte le tipologie di bicicletta elettrica. In Manuale Della Bici Elettrica 2019, 2nd ed.; Moma Studio: Milano, Italy, 2019; pp. 2-9.

4. Catalogo Delle Bici Elettriche 2019. La Guida Completa Alla Scelta Della E-Bike, EDITOR network BiciLive.it. 2019, pp. 144-145, 272-273, 284-285. Available online: http:/ / www.bicilive.it/ (accessed on 25 October 2019).

5. Tutto sulla Bicicletta Elettrica A Pedalata Assistita. Available online: http://ebike.bicilive.it/wikiebike/guida-bicicletta-elettricaa-pedalata-assistita/ (accessed on 11 October 2019).

6. Trasmissione Cardanica, Pro e Contro di una Scelta Fuori Dal Coro. Available online: https://www.italiaonroad.it/2013/09/21 /trasmissione-cardanica-pro-e-contro-di-una-scelta-fuori-dal-coro/ (accessed on 6 December 2019).

7. Frizziero, L.; Donnici, G.; Liverani, A.; Alessandri, G.; Menozzi, G.C.; Varotti, E. Developing Innovative Crutch Using IDeS (Industrial Design Structure) Methodology. Appl. Sci. 2019, 9, 5032. [CrossRef]

8. Frizziero, L.; Liverani, A.; Nannini, L. Design for Six Sigma (DFSS) Applied to a New Eco-Motorbike. Machines 2019, 7, 52. [CrossRef]

9. Liverani, A.; Caligiana, G.; Frizziero, L.; Francia, D.; Donnici, G.; Dhaimini, K. Design for Six Sigma (DFSS) for additive manufacturing applied to an innovative multifunctional fan. Int. J. Interact. Des. Manuf. (IJIDeM) 2019, 13, 309-330. [CrossRef]

10. Schmitt, F. Which is the Best Motor for Electric Vehicles (EVs) and Why? Available online: https://www.quora.com/Which-isthe-best-motor-for-electric-vehicles-EVs-and-why (accessed on 15 November 2019).

11. Gilbert, D. Motorcycle Frame Design, HS 009 789; National Highway Traffic Safety Administration: Washington, DC, USA, 1971.

12. Warner, J. The Handbook of Lithium-Ion Battery Pack Design; Elsevier Science: Amsterdam, The Netherlands, 20 May $2015 ;$ pp. 1-262. ISBN 9780128014561. eBook ISBN: 9780128016688.

13. Cocco, G. Motorcycle Design and Technology; Giorgio Nada Editore: Vimodrone, Italy, 2004; pp. 15-50. ISBN 978-88-7911-344-1.

14. Nicolò, F. Progettazione, Realizzazione e Verifica del Telaio del Progetto Motostudent; Università degli Studi di Padova: Padua, Italy, 2016.

15. Frizziero, L.; Donnici, G.; Francia, D.; Caligiana, G.; Gaddoni, A. Stylistic design engineering (SDE) for an innovative green vehicle following QFD and TRIZ applications. Int. J. Mech. Prod. Eng. Res. Dev. 2019, 9, 805-827.

16. Donnici, G.; Frizziero, L.; Liverani, A.; Galiè, G.; Lelli, F. A new SUV conceived by stylistic design engineering (SDE). In Proceedings of the 3rd Eu International Conference on Industrial Engineering and Operations Management, IEOM 2019, Western Bohemia, Czech Republic, 23-26 July 2019; pp. 2125-2142, Code 141178.

17. Frizziero, L.; Donnici, G.; Liverani, A.; Ximenes, N.M.A.; Secli' ${ }^{\prime}$, A.; Ticca, M. Stylistic design engineering (SDE) applied to a new E-segment sport Sedan. In Proceedings of the 3rd Eu International Conference on Industrial Engineering and Operations Management, IEOM 2019, Western Bohemia, Czech Republic, 23-26 July 2019; pp. 2371-2386, Code 14117.

18. Donnici, G.; Frizziero, L.; Francia, D.; Liverani, A.; Caligiana, G. TRIZ method for innovation applied to an hoverboard. Cogent Eng. 2018, 5, 1524537. [CrossRef]

19. Piancastelli, L.; Frizziero, L.; Donnici, G. Common rail diesel-automotive to aerial vehicle conversions: An update (Part II). ARPN J. Eng. Appl. Sci. 2015, 10, 3286-3294.

20. Piancastelli, L.; Frizziero, L.; Donnici, G. Common rail diesel-electric propulsion for small boats and yachts. ARPN J. Eng. Appl. Sci. 2015, 10, 2378-2385.

21. Piancastelli, L.; Frizziero, L.; Donnici, G. Common rail diesel-Automotive to aerial vehicle conversions: An update (Part I). ARPN J. Eng. Appl. Sci. 2015, 10, 2479-2487.

22. Frizziero, L.; Rocchi, I.; Donnici, G.; Pezzuti, E. Aircraft diesel engine turbocompound optimized. JP J. Heat Mass Transf. 2015, 11, 133-150. [CrossRef]

23. Piancastelli, L.; Frizziero, L.; Donnici, G. A new concept for low inertia electric turbocompounding in racing spark ignition engines. JP J. Heat Mass Transf. 2015, 12, 1-14. [CrossRef]

24. Donnici, G.; Frizziero, L.; Francia, D.; Liverani, A.; Caligiana, G. Project of inventive ideas through a TRIZ study applied to the analysis of an innovative urban transport means. Int. J. Manuf. Mater. Mech. Eng. 2018, 8, 1-24.

25. Richard, L. Martyn Kendrick, Natalia Vershinina Management; South-Western/Cengage Learning: Mason, OH, USA, 2010.

26. Frizziero, L. How Industrial Design Structure links to the Organization Process. In Proceedings of the 2nd African International Conference on Industrial Engineering and Operations Management, Harare, Zimbabwe, 7-10 December 2020. 